\title{
Bioconjugated Manganese Dioxide Nanoparticles Enhance Chemotherapy Response by Priming Tumor-Associated Macrophages toward M1-like Phenotype and Attenuating Tumor Hypoxia
}

\author{
Manli Song ${ }^{\# \dagger}$, Ting Liu ${ }^{\#}, \dagger$, Changrong Shi ${ }^{\dagger}$, Xiangzhong Zhang ${ }^{*}, \dagger$, and Xiaoyuan Chen ${ }^{*}, \neq$ \\ †State Key Laboratory of Molecular Vaccinology and Molecular Diagnostics \& Center for \\ Molecular Imaging and Translational Medicine, School of Public Health, Xiamen University, \\ Xiamen 361102, China \\ ‡Laboratory of Molecular Imaging and Nanomedicine, National Institute of Biomedical Imaging \\ and Bioengineering, National Institutes of Health, Bethesda, Maryland 20892, United States \\ \# These authors contributed equally to this work.
}

\section{Abstract}

Hypoxia promotes not only the invasiveness of tumor cells, but also chemoresistance in cancer. Tumor associated macrophages (TAMs) residing at the site of hypoxic region of tumors have been known to cooperate with tumor cells, and promote proliferation and chemoresistance. Therefore, there is an urgent need for new strategies to alleviate tumor hypoxia and enhance chemotherapy response in solid tumors. Herein, we have taken advantage of high accumulation of TAMs in hypoxic regions of tumor and high reactivity of manganese dioxide nanoparticles $\left(\mathrm{MnO}_{2} \mathrm{NPs}\right)$ toward hydrogen peroxide $\left(\mathrm{H}_{2} \mathrm{O}_{2}\right)$ for the simultaneous production of $\mathrm{O}_{2}$ and regulation of $\mathrm{pH}$ to effectively alleviate tumor hypoxia by targeted delivery of $\mathrm{MnO}_{2} \mathrm{NPs}$ to the hypoxic area. Furthermore, we also utilized the ability of hyaluronic acid (HA) modification in reprogramming anti-inflammatory, pro-tumoral M2 TAMs to pro-inflammatory, antitumor M1 macrophages to further enhance the ability of $\mathrm{MnO}_{2} \mathrm{NPs}$ to lessen tumor hypoxia and modulate chemoresistance. The HA-coated, mannanconjugated $\mathrm{MnO}_{2}$ particle (Man-HA- $\mathrm{MnO}_{2}$ ) treatment significantly increased tumor oxygenation and down-regulated hypoxia-inducible factor-1 $a$ (HIF-1 $a$ ) and vascular endothelial growth factor (VEGF) in the tumor. Combination treatment of the tumors with Man-HA- $\mathrm{MnO}_{2}$ NPs and doxorubicin significantly increased apparent diffusion coefficient (ADC) values of breast tumor, inhibited tumor growth and tumor cell proliferation as compared

\footnotetext{
*Corresponding Authors, tingliu20072008@yahoo.com. zhangxzh@xmu.edu.cn. shawn.chen@nih.gov. . Supporting Information

The Supporting Information is available free of charge on the ACS Publications website at DOI: 10.1021/acsnano.5b06779. Characterization of Man-HA-MnO 2 NPs, cell binding and uptake of Man-HA-MnO 2 NPs, reaction of Man-HA-MnO $2 \mathrm{NPs}^{-\mathrm{H}}$ toward $\mathrm{H}_{2} \mathrm{O}_{2}$, the $T_{1}$ - and $T_{2}$-weighted MR signal, and $r_{1}$ and $r_{2}$ relaxivity vs Mn concentration for Man-HA-MnO 2 NP solution, Man-HA$\mathrm{MnO}_{2} \mathrm{NP}$ solution treated with $\mathrm{H}_{2} \mathrm{O}_{2}$, and $\mathrm{M} 2$ macrophages incubated with Man-HA-MnO $2 \mathrm{NPs}$, and effect on tumor growth and cell viability after treatment with Dox and Man-HA-MnO 2 NPs (PDF)

Notes

The authors declare no competing financial interest.
} 
with chemotherapy alone. In addition, the reaction of Man-HA- $\mathrm{MnO}_{2} \mathrm{NPs}$ toward endogenous $\mathrm{H}_{2} \mathrm{O}_{2}$ highly enhanced $T_{1}$ - and $T_{2}$-MRI performance for tumor imaging and detection.

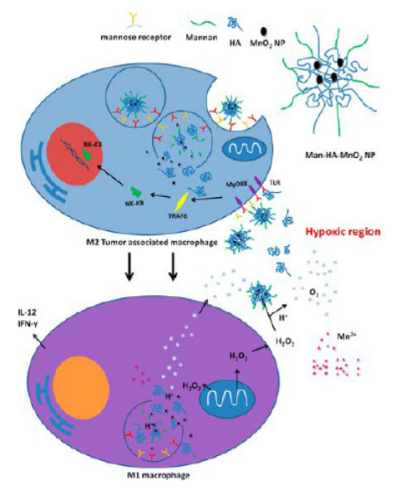

\section{Keywords}

hypoxia; tumor associated macrophages (TAMs); chemotherapy response; manganese dioxide $\left(\mathrm{MnO}_{2}\right)$; hyaluronic acid (HA); mannose receptor

Hypoxia, defined as a decrease of tissue oxygen level, is a characteristic feature of locally advanced solid tumors, resulting from an imbalance between the intake and consumption of oxygen caused by abnormal vessels in the tumor and the rapid proliferation of cancer cells. ${ }^{1}$ Hypoxia represents a key microenvironmental stressor governing multiple phenomena associated with tumor progression such as proliferation, angiogenesis and metastasis. ${ }^{2}$ Hypoxia not only promotes the invasiveness of malignant cells, but also negatively impacts on the efficacy of radio- and chemotherapy, ${ }^{3}$ and the survival rate of patients with severely hypoxic tumors is lower than patients with less hypoxic tumors. ${ }^{4}$ Therapeutic resistance caused by hypoxia is partly because some drugs and radiation require oxygen to be maximally cytotoxic. The decreased drug bioavailability because of abnormal vascularization in hypoxic region of tumors also contributes to chemoresistance. Various strategies have been proposed to alleviate tumor hypoxia to surmount hypoxia-associated therapeutic resistance, including hyperbaric oxygen therapy, ${ }^{5}$ combination of oxygen-rich gas and vasodilating agents, ${ }^{6}$ and reducing the rate of oxygen consumption. ${ }^{7}$ Unfortunately, the utility of these methods in clinical settings is limited because of safety concerns, limited $\mathrm{O}_{2}$ loading capacity, and inefficient drug delivery to the hypoxic region. Therefore, there is an urgent need for new strategies to alleviate tumor hypoxia in order to enhance chemotherapy response in solid tumors.

Hypoxic regions of solid tumors are often characterized by high accumulation of macrophages. ${ }^{8}$ Tumor hypoxia is instrumental in macrophage recruitment and polarization. ${ }^{9}$ The infiltrated macrophages initially have an M1-polarized phenotype. However, continued presence in tumor microenvironment polarizes them to M2-skewed tumor-associated macrophages (TAMs). ${ }^{10}$ The classic pro-inflammatory M1 phenotype exerts antiproliferative and cytotoxic activities, resulting partly from their ability to secrete reactive nitrogen and oxygen species (e.g., hydrogen peroxide, NO, peroxynitrite, and superoxide) and proinflammatory cytokines (e.g., TNF, IL-1, and IL-6). ${ }^{11}$ In contrast, the M2 "repair" 
designation broadly refers to macrophages that function in constructive processes like wound healing and tissue repair, and those that turn off damaging immune system activation by producing anti-inflammatory cytokines like IL-10. ${ }^{11,12}$ TAMs are known to respond rapidly to hypoxia with altered gene expression, such as up-regulation of hypoxia-inducible factors (HIFs), vascular endothelial growth factor (VEGF) and matrix metalloproteinase (MMP)-7. The educated TAMs by hypoxia contribute to tumor progression via several mechanisms, including induction of angiogenesis, remodeling of the extracellular matrix, stimulation of cancer cell proliferation and metastasis, and the inhibition of adaptive immunity. ${ }^{9,13}$ Furthermore, recent evidence shows that TAMs may also be associated with chemoresistance of cancer. ${ }^{14,15}$ The strong tumor hypoxia and a high density of hypoxic TAMs have been shown to correlate with a decreased survival rate. Given their propensity for hypoxic areas, it has been suggested that macrophages could be used as delivery vehicles to hypoxia. ${ }^{16}$ In addition, re-educating TAMs is proposed to be an efficient strategy to inhibit tumor progression and metastasis in breast cancer, ${ }^{3,17}$ which would regulate hypoxia and modulate tumor microenvironment. Here, we took advantages of high accumulation of TAMs in the hypoxic region of tumor and high reactivity of manganese dioxide nanoparticles $\left(\mathrm{MnO}_{2} \mathrm{NPs}\right)$ toward hydrogen peroxide $\left(\mathrm{H}_{2} \mathrm{O}_{2}\right)^{18,19}$ for the simultaneous production of $\mathrm{O}_{2}$ and regulation of $\mathrm{pH}$ to effectively lessen tumor hypoxia by targeted delivery of $\mathrm{MnO}_{2} \mathrm{NPs}$ to hypoxia. Furthermore, we also utilized the ability of hyaluronic acid (HA) modification in reprogramming anti-inflammatory, pro-tumoral M2 TAMs to proinflammatory, antitumor M1 macrophages ${ }^{20,21}$ to further enhance the ability of Man-HA$\mathrm{MnO}_{2} \mathrm{NPs}$ to alleviate tumor hypoxia and modulate chemoresistance (Scheme 1).The high level of $\mathrm{H}_{2} \mathrm{O}_{2}$ secreted by TAMs activated by HA-modified $\mathrm{MnO}_{2}$ NPs allowed sufficient reaction with Man-HA- $\mathrm{MnO}_{2} \mathrm{NPs}$ to release large amount of $\mathrm{O}_{2}$. In addition, the released $\mathrm{Mn}^{2+}$ ions from the reaction of Man-HA- $\mathrm{MnO}_{2} \mathrm{NPs}$ toward $\mathrm{H}_{2} \mathrm{O}_{2}$ highly enhanced $T_{1}$ - and $T_{2}$-MRI performance for tumor imaging and detection.

Manganese(II) salts have been demonstrated as alternative contrast agents (CAs) for $T_{1^{-}}$ weighted MRI as a potential substitute for clinically used gadolinium $(\mathrm{Gd})$-based CAs due to their improved biocompatibility over Gd-based agents, such as $\mathrm{MnCl}_{2},{ }^{22}$ manganese chelates ${ }^{23,24}$ and $\mathrm{MnO}$ nanoparticles. ${ }^{25}$ Although $\mathrm{MnO}_{2}$ nanoparticles have considerably lower $T_{1}$-MRI performance than commercial Gd-based $\mathrm{CAs}, \mathrm{MnO}_{2}$ has the ability to react quickly with $\mathrm{H}_{2} \mathrm{O}_{2}$ under acidic condition and simultaneously produce $\mathrm{O}_{2}$ and $\mathrm{Mn}^{2+}$ ions that significantly enhance $T_{1}$-MRI performances for tumor imaging and detection. ${ }^{26} \mathrm{In}$ addition, manganese is an essential element for physiological metabolism and in vivo biological systems can efficiently control its homeostasis. Thus, suitably surface modified $\mathrm{MnO}_{2}$ NPs would be a promising $T_{1}$-weighted MRI CA for tumor imaging and tumor hypoxia detection.

\section{RESULTS AND DISCUSSION Characteristics of Man-HA-MnO 2 NPs}

The synthesis of $\mathrm{MnO}_{2}$ nanoparticles was conducted according to a reported procedure with some modifications. ${ }^{19}$ Typically, $\mathrm{MnO}_{2}$ nanoparticles were prepared by reducing manganese permanganate $\left(\mathrm{KMnO}_{4}\right)$ to $\mathrm{MnO}_{2}$ with cationic polyelectrolyte poly-(allylamine 
hydrochloride) (PAH) (Figure 1A). The poly-electrolyte-coated $\mathrm{MnO}_{2}$ colloidal nanoparticles are stable and dispersed well in distilled deionized (DDI) water with an average nanoparticle (NP) size of $15 \mathrm{~nm}$ (Figure 1B) and positive charge (zeta potential, $+28.7 \mathrm{mV}$ ) (Figure 1C), while in saline and cell medium, they are unstable (Figure 1D), causing cell toxicity. It is reported that hyaluronic acid (HA) has immunotoxicological effect on macrophages, which can activate macrophages and increase the production of endogenous reactive oxygen species (ROS). ${ }^{20,21}$ Herein, we question whether HA has the ability to shape the inflammatory behavior of TAMs and contribute to macrophage polarization. Furthermore, to improve the biocompatibility of $\mathrm{MnO}_{2} \mathrm{NPs}$, we conjugated HA to polyelectrolyte-coated $\mathrm{MnO}_{2} \mathrm{NPs}$ and obtained HA-MnO${ }_{2}$ NPs (Figure S1A). The HA$\mathrm{MnO}_{2}$ nanoparticles were around $180 \mathrm{~nm}$ in size, negatively charged $(-36.5 \mathrm{mV})$, and stable in cell medium and saline (Figure 1), while maintaining the reactivity of $\mathrm{MnO}_{2}$ toward $\mathrm{H}_{2} \mathrm{O}_{2}$ to produce $\mathrm{O}_{2}$. TAMs with $\mathrm{M} 2$ phenotype are characterized by high expression of mannose receptors. ${ }^{27}$ For targeted delivery of $\mathrm{HA}-\mathrm{MnO}_{2}$ NPs to TAMs, we coated $\mathrm{HA}-\mathrm{MnO}_{2} \mathrm{NPs}$ with mannan that targets to mannose receptor on the surface of TAMs. Mannan modification masked the negative charges on the $\mathrm{HA}-\mathrm{MnO}_{2} \mathrm{NPs}$ and increased their size as well (Figure 1, Figure S1B). The total ligand-to-carrier weight ratio was optimized by measuring the change in zeta potential (Figure S1C). The optimum ratio was obtained at 2:5. Mean particle size and zeta potential of $\mathrm{MnO}_{2}$ nanoparticles, $\mathrm{HA}-\mathrm{MnO}_{2}$ nanoparticles and mannanmodified $\mathrm{HA}-\mathrm{MnO}_{2}$ nanoparticles (Man-HA- $\mathrm{MnO}_{2} \mathrm{NPs}$ ) were summarized in Table 1. Cytotoxicity of Man-HA- $\mathrm{MnO}_{2} \mathrm{NPs}$ and $\mathrm{MnO}_{2} \mathrm{NPs}$ was assessed by a MTT assay, and the results showed that after $4 \mathrm{~h}$ of incubation, over $90 \%$ of cells remained alive in the presence of $10 \mathrm{mM}$ Mn equivalent of Man-HA- $\mathrm{MnO}_{2} \mathrm{NPs}$, whereas only $40 \%$ cells survived at the same Mn concentration of $\mathrm{MnO}_{2}$ NPs without HA coating (Figure S1D).

To investigate whether conjugation of mannan on the surface of NPs enhances the binding to $\mathrm{M} 2$ macrophages, the association of Man-HA- $\mathrm{MnO}_{2} \mathrm{NPs}$ and $\mathrm{HA}-\mathrm{MnO}_{2} \mathrm{NPs}$ with M2 macrophages was compared by confocal microscopy. M2 macrophages were generated by pretreating RAW264.7 cells with IL-4 for $24 \mathrm{~h}$. After incubation of M2 macrophages with

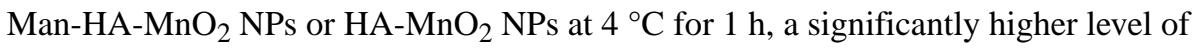
association of fluorescently labeled Man-HA- $\mathrm{MnO}_{2} \mathrm{NPs}$ with $\mathrm{M} 2$ macrophages in culture was observed, as compared with macrophages incubated with untargeted control $\mathrm{HA}-\mathrm{MnO}_{2}$ NPs (Figure S2A). The association of nanoparticles was further quantified by measuring the percentage of positive cells and fluorescence intensity using flow cytometry. As shown in Figure S2B and C, after $1 \mathrm{~h}$ incubation, 5-fold more positive cells in the Man-HA- $\mathrm{MnO}_{2} \mathrm{NP}$ group were found than those in the $\mathrm{HA}-\mathrm{MnO}_{2} \mathrm{NP}$ group. The mean fluorescence intensity of macrophages with Man-HA-MnO${ }_{2} \mathrm{NPs}$ was $180 \mathrm{au}$, while that for $\mathrm{HA}-\mathrm{MnO}_{2} \mathrm{NPs}$ was only 11 au ( $p=0.002$, Figure S2C). These results demonstrate the specificity of Man-HA- $\mathrm{MnO}_{2}$ NPs toward M2 macrophages in vitro.

As shown in Scheme 1, the reaction between $\mathrm{MnO}_{2}$ and $\mathrm{H}_{2} \mathrm{O}_{2}$ leads to the decomposition of $\mathrm{H}_{2} \mathrm{O}_{2}$, the consumption of $\mathrm{H}^{+}$ions, and simultaneous production of $\mathrm{O}_{2}$ and $\mathrm{Mn}^{2+}$ ions. The high reactivity of $\mathrm{MnO}_{2}$ toward $\mathrm{H}_{2} \mathrm{O}_{2}$ and its ability in fully recovering the oxygen therein render $\mathrm{MnO}_{2}$ attractive in applications as catalysts and batteries. ${ }^{18}$ To investigate whether HA conjugation and mannan modification would affect the reactivity of $\mathrm{MnO}_{2}$ toward $\mathrm{H}_{2} \mathrm{O}_{2}$, we incubated Man-HA- $\mathrm{MnO}_{2}$ NPs with $\mathrm{H}_{2} \mathrm{O}_{2}$ in phosphate buffer at $\mathrm{pH} 6.5$, and measured 
$\mathrm{H}_{2} \mathrm{O}_{2}$ level, change of $\mathrm{pH}$, and the production of $\mathrm{Mn}^{2+}$ continuously. We observed that 300 $\mu \mathrm{M} \mathrm{H} \mathrm{H}_{2} \mathrm{O}_{2}$ was able to be completely quenched by $50 \mu \mathrm{M}$ of Man-HA- $\mathrm{MnO}_{2} \mathrm{NPs}$ at $\mathrm{pH} 6.5$ in $60 \mathrm{~min}$ (Figure S3A), accompanied by an increase in the $\mathrm{pH}$ of phosphate buffer from 6.5 to 7.8 (Figure $\mathrm{S} 3 \mathrm{~B}$ ). $\mathrm{MnO}_{2}$ has considerably low $T_{1^{-}}$and $T_{2}$-MRI performances. Once reduced into $\mathrm{Mn}^{2+}$ ions, they exhibit much stronger enhancement in both $T_{1}$ - and $T_{2^{-}}$ weighted MRI than $\mathrm{MnO}_{2} \cdot{ }^{28}$ Therefore, the $\mathrm{Mn}^{2+}$ ion generating properties of the NPs can be investigated by measuring the changes of $T_{1}$ and $T_{2}$ signals. The continuous enhancement in $T_{1}$ and $T_{2}$ signals was obviously a result of $\mathrm{Mn}^{2+}$ ion generation from the reaction of Man-HA- $\mathrm{MnO}_{2} \mathrm{NPs}$ with $\mathrm{H}_{2} \mathrm{O}_{2}$ (Figure $\mathrm{S} 3 \mathrm{C}, \mathrm{D}$ ). These data suggest that $\mathrm{H}_{2} \mathrm{O}_{2}$ can easily diffuse across the polyelectrolyte-HA complex and have access to the reactive sites of $\mathrm{MnO}_{2}$. Furthermore, the rapid reaction was not affected by HA conjugation and mannan modification as $\mathrm{H}_{2} \mathrm{O}_{2}$ was quenched by Man-HA-MnO${ }_{2} \mathrm{NPs}$ and $\mathrm{MnO}_{2} \mathrm{NPs}$ at the same rate, and the consumption of $\mathrm{H}^{+}$ions and production of $\mathrm{Mn}^{2+}$ ions upon the reaction of Man-HA- $\mathrm{MnO}_{2} \mathrm{NPs}$ toward $\mathrm{H}_{2} \mathrm{O}_{2}$ were similar to that of $\mathrm{MnO}_{2}$ at the same concentration.

To evaluate the effectiveness of Man-HA- $\mathrm{MnO}_{2} \mathrm{NPs}$ as a $\mathrm{H}_{2} \mathrm{O}_{2}$-active MRI contrast agent, longitudinal and transverse relaxation rates of Man-HA- $\mathrm{MnO}_{2} \mathrm{NPs}$ after being reduced by $\mathrm{H}_{2} \mathrm{O}_{2}$ were examined. Longitudinal relaxivity $r_{1}$ and transverse relaxivity $r_{2}$, obtained by measuring the relaxation rate as a function of $\mathrm{Mn}$ concentration showed marked enhancement, when Man-HA- $\mathrm{MnO}_{2} \mathrm{NPs}$ were reduced to $\mathrm{Mn}^{2+}$ by $\mathrm{H}_{2} \mathrm{O}_{2}$. After $\mathrm{H}_{2} \mathrm{O}_{2}$ reduction, the $r_{1}$ and $r_{2}$ values of Man-HA-MnO $\mathrm{MPs}_{2} \mathrm{NP}$ were as high as 7.71 and $45.06 \mathrm{mM}^{-1}$ $\mathrm{s}^{-1}$ at $25^{\circ} \mathrm{C}$ and $9.4 \mathrm{~T}$ field strength, respectively, which were 64 - and 109 -fold higher than those before $\mathrm{H}_{2} \mathrm{O}_{2}$ reduction $\left(r_{1}=0.12 \mathrm{mM}^{-1} \mathrm{~s}^{-1}, r_{2}=0.41 \mathrm{mM}^{-1} \mathrm{~s}^{-1}\right.$, Figure $\left.\mathrm{S} 4\right)$. The $r_{1}$ value is comparable to that of commercial Gd-DPTA $\left(r_{1}=5.6 \mathrm{mM}^{-1} \mathrm{~s}^{-1}\right.$ at $\left.25^{\circ} \mathrm{C}, 9.4 \mathrm{~T}\right)$. The low $r_{1}$ value of initial Man-HA- $\mathrm{MnO}_{2} \mathrm{NP}$ is due to the high valence (IV) of manganese and shielding from the aqueous environment. ${ }^{29,30}$ Once Man-HA- $\mathrm{MnO}_{2} \mathrm{NPs}$ are reduced, released $\mathrm{Mn}^{2+}$ ions easily access to surrounding water molecules and significantly enhance water proton relaxation. Furthermore, each ion can serve as an MRI contrast agent and, thus, dramatically enhances transverse and longitudinal relaxation times of the protons.

\section{In Vitro Reaction of Man-HA-MnO $2 ~ N P s$ toward $\mathrm{H}_{2} \mathrm{O}_{2}$}

$\mathrm{MnO}_{2}$ has shown high reactivity and specificity toward $\mathrm{H}_{2} \mathrm{O}_{2}$ to produce $\mathrm{O}_{2}$ and $\mathrm{Mn}^{2+}$ by consuming $\mathrm{H}^{+}$ions. The production of $\mathrm{O}_{2}$ and increase in the local $\mathrm{pH}$ by reaction of $\mathrm{MnO}_{2}$ toward $\mathrm{H}_{2} \mathrm{O}_{2}$ can be particularly useful for improving oxygen level and regulation of local $\mathrm{pH}$ in tumor tissue, which would provide opportunity to attenuate tumor hypoxia and modulate solid tumor microenvironment. It is known that HA has immunotoxicological effects on macrophages, which can activate macrophages and increase endogenous $\mathrm{H}_{2} \mathrm{O}_{2}$ production. ${ }^{21}$ We hypothesized that the Man-HA- $\mathrm{MnO}_{2} \mathrm{NPs}$ could be taken up by M2 macrophages and lead to significantly elevated production of $\mathrm{H}_{2} \mathrm{O}_{2}$. We also questioned whether NPs could react quickly with $\mathrm{H}_{2} \mathrm{O}_{2}$ produced in situ. To test the hypothesis and address the question, we first examined the cellular uptake of the NPs by incubating M2 macrophages with fluorescently labeled Man-HA- $\mathrm{MnO}_{2} \mathrm{NPs}$ at $37^{\circ} \mathrm{C}$, and observed significant cellular uptake of the NPs after incubation for $1 \mathrm{~h}$ (Figure S5A). We then incubated M2 macrophages (generated from RAW264.7 cells) with Man-HA-MnO ${ }_{2}$ NPs at $\mathrm{pH} 6.5$, and measured $\mathrm{H}_{2} \mathrm{O}_{2}$ level, changes of $\mathrm{pH}$, and the production of $\mathrm{Mn}^{2+}$ continuously. 
After an initial decrease in $\mathrm{H}_{2} \mathrm{O}_{2}$ level in the first 20 min, a continuous increase in $\mathrm{H}_{2} \mathrm{O}_{2}$ level in 60 min was observed and accompanied by an increase in the $\mathrm{pH}$ of cell culture medium from pH 6.5 to 7.8 and continuous enhancements in $T_{1}$ - and $T_{2}$-weighted MRI contrast signals, indicating that endogenous $\mathrm{H}_{2} \mathrm{O}_{2}$ released by macrophages in vitro is sufficient to react with NPs. In addition, to investigate the effect of Man-HA-MnO $\mathrm{O}_{2}$ NPs on $\mathrm{H}_{2} \mathrm{O}_{2}$ production by $\mathrm{M} 2$ macrophages, we determined $\mathrm{H}_{2} \mathrm{O}_{2}$ levels of the medium after incubating M2 macrophages with Man-HA- $\mathrm{MnO}_{2} \mathrm{NPs}$ at different concentrations $(0.5,2.5$, and $5 \mu \mathrm{M}$ ). We observed elevated level of $\mathrm{H}_{2} \mathrm{O}_{2}$ with increased amount of Man-HA- $\mathrm{MnO}_{2}$ NPs after $1 \mathrm{~h}$ incubation (Figure S5C), indicating that Man-HA-MnO ${ }_{2} \mathrm{NPs}$ have the ability to increase endogenous $\mathrm{H}_{2} \mathrm{O}_{2}$ production.

\section{Biodistribution and Tumor Accumulation of Man-HA-MnO 2 NPs}

Noninvasive near-infrared fluorescence (NIRF) optical imaging was utilized to monitor the in vivo biodistribution and tumor accumulation of Man-HA- $\mathrm{MnO}_{2} \mathrm{NPs}$. We injected 4T1

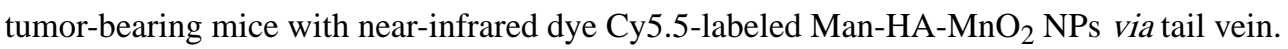
The in vivo NIRF optical images demonstrated steady increase of tumor uptake of Man-HA$\mathrm{MnO}_{2}$ NPs after intravenous (iv) injection, which peaked at $6 \mathrm{~h}$ and then plateaued over time (Figure 2A,B). At $24 \mathrm{~h}$ postinjection, tumors and major organs were excised for ex vivo NIRF imaging to determine the tissue distribution of Man-HA-MnO $\mathrm{O}_{2} \mathrm{NPs}$. As shown in Figure 2C,D, Man-HA-MnO ${ }_{2}$ NPs demonstrated good tumor accumulation and relatively low liver uptake. To confirm tumor accumulation of Man-HA-MnO${ }_{2} \mathrm{NPs}$, we also investigated the biodistribution of free Cy5.5 dye and observed an obvious distinction of tumor accumulation between Man-HA-MnO 2 NPs and the free dye. Free Cy5.5 dye showed an initial maximal tumor fluorescence followed by rapid clearance with time (Figure 2A,B). Biodistribution of free Cy5.5 at $24 \mathrm{~h}$ postinjection (pi) showed high kidney accumulation and low tumor retention (Figure 2C,D), indicating that free Cy5.5 was mainly eliminated from the renal route. These data demonstrated that the Cy5.5 label was not removed from NPs prematurely and the high fluorescence intensity in the tumor was resulted from high accumulation of Man-HA- $\mathrm{MnO}_{2} \mathrm{NP}$, not free Cy5.5. The biodistribution of Man-HA- $\mathrm{MnO}_{2}$ NPs was confirmed by ICP-MS for quantification of $\mathrm{Mn}^{2+}$ (Figure S6).

In addition, to determine whether Man-HA-MnO 2 NPs can be uptaken by TAMs in the tumor, 4T1 tumor mice were iv injected with Cy5.5 dye labeled Man-HA- $\mathrm{MnO}_{2} \mathrm{NPs}$. Tumors were collected and subjected to immunostaining with CD206 M2 macrophage marker at $24 \mathrm{~h}$ after injection. The microscopic analysis of tumor sections indicated that Man-HA- $\mathrm{MnO}_{2}$ NPs were taken up by TAMs which were identified by the staining of CD206 M2 macrophage marker (Figure 2E). The data demonstrated that Man-HA-MnO ${ }_{2}$ NPs could be successfully delivered to TAMs in vivo, which would allow the reaction of Man-HA- $\mathrm{MnO}_{2} \mathrm{NPs}$ toward endogenous $\mathrm{H}_{2} \mathrm{O}_{2}$, leading to $\mathrm{O}_{2}$ release in the hypoxic tumor region.

\section{Man-HA-MnO ${ }_{2}$ NPs Prime Tumor Associated Macrophages toward M1-like Macrophages}

It is known that HA has immunotoxicological effect toward macrophages, which can activate macrophages and increase endogenous $\mathrm{H}_{2} \mathrm{O}_{2}$ production. ${ }^{20,21}$ Interestingly, we observed that Man-HA- $\mathrm{MnO}_{2} \mathrm{NPs}$ can also significantly increase $\mathrm{H}_{2} \mathrm{O}_{2}$ production. We 
further questioned whether Man-HA- $\mathrm{MnO}_{2} \mathrm{NPs}$ have immunological effect on macrophage polarization. We pretreated RAW264.7 cells with IL-4 for $24 \mathrm{~h}$ to generate M2 macrophages, ${ }^{31}$ then incubated them with Man-HA-MnO ${ }_{2}$ NPs (5 $\mu \mathrm{M}$ Mn and $\left.15 \mu \mathrm{M} \mathrm{HA}\right)$, $\mathrm{MnO}_{2}$ NPs $(5 \mu \mathrm{M} \mathrm{Mn}), \mathrm{HA}(15 \mu \mathrm{M})$ or mannan $(3 \mu \mathrm{M})$ for $1 \mathrm{~h}$, followed by incubation with the antibodies against different cell markers: iNOS was chosen as a typical marker for M1 phenotype, while CD206 was for M2. Flow cytometry analysis was performed to quantify the expression M1/M2 ratio. We observed that expression of iNOS was significantly increased on macrophages treated with Man-HA- $\mathrm{MnO}_{2}$ NPs and $\mathrm{HA}$ but not $\mathrm{MnO}_{2}$ NPs at the same Mn concentration, while their expression of CD206 was decreased, suggesting that Man-HA- $\mathrm{MnO}_{2}$ NPs induced the polarization of M2 macrophages to M1 (Figure 3A). Mannan alone showed no effect on macrophage polarization. Moreover, this M1 polarization was further confirmed by the cytokine secretion experiment. After incubation with Man-HA$\mathrm{MnO}_{2} \mathrm{NPs}$ or HA, macrophages secreted higher level of IL-12, a typical M1-type cytokine, and lower level of IL-10, a typical M2-type cytokine, than the untreated ones (Figures 3C and S7). The TAMs were collected and the effect of Man-HA-MnO 2 NPs on macrophage polarization was confirmed (Figure S8).

Upon activation, $\mathrm{M} 1$ macrophages produce high level of $\mathrm{H}_{2} \mathrm{O}_{2}$. To investigate the effect of Man-HA- $\mathrm{MnO}_{2} \mathrm{NPs}$ on $\mathrm{H}_{2} \mathrm{O}_{2}$ production, we incubated $\mathrm{M} 2$ macrophages generated from RAW264.7 cells with Man-HA- $\mathrm{MnO}_{2} \mathrm{NPs}$ or $\mathrm{MnO}_{2}$ NPs at different concentrations $(0.5$, 2.5 , and $5 \mu \mathrm{M} \mathrm{Mn}$ ) for $1 \mathrm{~h}$, and then determined $\mathrm{H}_{2} \mathrm{O}_{2}$ level in the medium. After $1 \mathrm{~h}$ incubation, the level of $\mathrm{H}_{2} \mathrm{O}_{2}$ was significantly increased with increasing amount of ManHA- $\mathrm{MnO}_{2} \mathrm{NPs}$, while $\mathrm{MnO}_{2} \mathrm{NPs}$ alone showed no effect on $\mathrm{H}_{2} \mathrm{O}_{2}$ production. The $\mathrm{H}_{2} \mathrm{O}_{2}$ production in a Man-HA- $\mathrm{MnO}_{2} \mathrm{NP}$ dose dependent manner further confirmed that $\mathrm{M} 1$ polarization was induced by Man-HA-MnO 2 NPs (Figure S5C).

To further evaluate the effect of Man-HA- $\mathrm{MnO}_{2}$ NPs on polarization of TAMs in vivo, 4T1 tumor mice were iv injected with $13.2 \mathrm{mg} / \mathrm{kg}$ Man-HA- $\mathrm{MnO}_{2} \mathrm{NPs}$. Tumors were collected and subjected to immunostaining with CD206 and IL-10 M2 macrophage markers and iNOS and IL-12 M1 macrophage markers at $48 \mathrm{~h}$ after injection. Similar to the in vitro results, the percentage of M2 macrophages in tumors decreased, while that of M1 macrophages increased. TAMs are known to be prominent in hypoxic regions proximal to sites of necrosis and poor vascularization. TAM accumulation also often occurs in margination zones that surround islands of burgeoning tumor cells and in association with the tumor vasculature. While M1 macrophages are known to preferentially concentrate in margination zones surrounding tumor islands. We observed that the distribution of M2 macrophages was decreased in the hypoxic region, while $\mathrm{M} 1$ macrophages increased after Man-HA- $\mathrm{MnO}_{2} \mathrm{NP}$ administration (Figure 4A). To quantify this observed phenomenon, a multimarker flow cytometry protocol was performed to determine macrophage population in the tumors. The ratio of M2 macrophages to M1 macrophages (M2/M1) was calculated. A decrease in $\mathrm{M} 2 / \mathrm{M} 1$ ratio was observed after Man-HA- $\mathrm{MnO}_{2} \mathrm{NP}$ administration (Figure 4B). These data indicate that Man-HA- $\mathrm{MnO}_{2}$ NPs can successfully skew TAMs away from the M2 phenotype to a tumor-inhibiting M1 phenotype. In addition, the level of $\mathrm{H}_{2} \mathrm{O}_{2}$ in the tumors after Man-HA- $\mathrm{MnO}_{2} \mathrm{NP}$ treatment was significantly increased in a NP dose dependent manner, further suggesting that Man-HA- $\mathrm{MnO}_{2} \mathrm{NPs}$ can induce TAMs to M1 polarization (Figure S6). The high level of $\mathrm{H}_{2} \mathrm{O}_{2}$ secreted by Man-HA-MnO $\mathrm{O}_{2}$ NPs activated TAMs would 
provide large amount of $\mathrm{O}_{2}$ release by reaction with Man-HA- $\mathrm{MnO}_{2} \mathrm{NPs}$ in the hypoxic region of the tumor.

The high molecular weight hyaluronan (HA), a ubiquitously distributed extracellular matrix component, plays a critical role in ensuring tissue integrity and water balance. However, upon tissue injury, breakdown products of the extracellular matrix (lower molecular weight fragments) in turn activate an innate immune response. A large body of literature pointed out that low molecular weight HA (LMW HA) may function as an alarm signal to the immune system, particularly for monocytes/macrophages,${ }^{20,21,32,33}$ and that LMW HA may activate the innate immune response via a TLR2-MyD88-IRAK1-TRAF6-PKC $\zeta$-NK- $\kappa$ B or TLR4TRIF-TBK1-IRF3-dependent pathway. ${ }^{32,33}$ Furthermore, HA-based nanoparticles were found to exert immunotoxicological effects on macrophages. In the present study, we investigated the immunological effect of HA on macrophage polarization and observed that expression of iNOS was significantly up-regulated, while the expression of CD206 was reduced after HA treatment (Figure 3A). Furthermore, after incubation with HA, macrophages secreted higher level of IL-12 and lower level of IL-10 than the untreated ones (Figures $3 \mathrm{C}$ and $\mathrm{S} 7$ ), indicating that $\mathrm{HA}$ has the ability to prime M2 macrophages toward M1 phenotype. The immunological effect of HA on macrophage polarization may account for the ability of our Man-HA-MnO${ }_{2}$ NPs in changing TAM polarization from the M2 phenotype to a tumor-inhibiting M1 phenotype, since the same effect was not found after giving $\mathrm{MnO}_{2}$ NPs. In addition, we observed that the effect of HA on macrophage polarization was not as strong as Man-HA- $\mathrm{MnO}_{2} \mathrm{NPs}$ at the same HA concentration. Higher uptake of Man-HA- $\mathrm{MnO}_{2}$ NPs by macrophages may explain the stronger immunological effect of Man-HA- $\mathrm{MnO}_{2}$ NPs than HA, since macrophages prefer to recognize and take up bigger particles.

\section{Effect of Man-HA-MnO ${ }_{2}$ NPs on MR Signal}

The $\mathrm{MnO}_{2}$ NPs have lower $T_{1}$ and $T_{2}$ signals than free $\mathrm{Mn}^{2+}$ ions at the same manganese concentration because of the high valence (IV) of manganese. ${ }^{29,30} \mathrm{In}$ addition, Mn atoms in $\mathrm{MnO}_{2}$ nanoparticles are coordinated in octahedral geometry to six oxygen atoms and shielded from aqueous environment, making no contribution to the protons' longitudinal or transverse relaxation. ${ }^{28}$ Once $\mathrm{MnO}_{2} \mathrm{NPs}$ are reduced, $\mathrm{Mn}^{2+}$ ions are easily accessible to surrounding water molecules and significantly enhance water proton relaxation. Besides being an MRI contrast agent, the production of $\mathrm{Mn}^{2+}$ ions would be a suitable indicator for the reaction of $\mathrm{MnO}_{2} \mathrm{NPs}$ toward $\mathrm{H}_{2} \mathrm{O}_{2}$, which was accompanied by $\mathrm{O}_{2}$ release. The in vivo NIRF optical images have demonstrated steady increase of tumor uptake of Man-HA- $\mathrm{MnO}_{2}$ NPs until reaching a plateau at $6 \mathrm{~h}$ after iv injection. Therefore, to investigate the reaction of Man-HA- $\mathrm{MnO}_{2}$ NPs toward $\mathrm{H}_{2} \mathrm{O}_{2}$ in vivo and evaluate whether Man-HA- $\mathrm{MnO}_{2} \mathrm{NPs}$ is suitable for tumor imaging, 4T1 tumor mice were treated with Man-HA- $\mathrm{MnO}_{2} \mathrm{NPs}$ at different doses $(3.3,13.2$, and $26.4 \mathrm{mg} / \mathrm{kg})$ and subjected to MRI before and $6 \mathrm{~h}$ postinjection. We observed significant enhancement of $T_{1}$ and $T_{2}$ signals of tumors and dramatic changes in $T_{1}$ and $T_{2}$ values of tumors at $6 \mathrm{~h}$ after injection (Figure 5). Furthermore, the enhancement of $T_{1}$ - and $T_{2}$-weighted MRI contrast signals of tumors was in a NP dose dependent manner. A linear association between the NP dose and the change in the $T_{1}$ and $T_{2}$ relaxation rate $\left(\Delta T_{1}\right.$ and $\left.\Delta T_{2}\right)$ of tumor was observed, indicating that Man- 
HA- $\mathrm{MnO}_{2}$ NPs can act as a $\mathrm{H}_{2} \mathrm{O}_{2}$-active MRI contrast agent. These data also demonstrate that Man-HA- $\mathrm{MnO}_{2}$ NPs could react quickly with endogenous $\mathrm{H}_{2} \mathrm{O}_{2}$ and produce $\mathrm{Mn}^{2+}$ in the tumor. Besides large amount of $\mathrm{Mn}^{2+}$ generation, the dramatic enhancement of $T_{1}$ - and $T_{2}$-weighted MRI contrast would be attributed to the significantly high level of $\mathrm{H}_{2} \mathrm{O}_{2}$ released by skewed M1 macrophages, which was much higher than that of untreated tumors and led to quick reaction with Man-HA- $\mathrm{MnO}_{2}$.

The feasibility of the Man-HA- $\mathrm{MnO}_{2}$ NPs for cellular MRI was also evaluated by examining M2 macrophages incubated with Man-HA- $\mathrm{MnO}_{2} \mathrm{NPs}$ at different concentrations for $1 \mathrm{~h}$. The reaction of Man-HA- $\mathrm{MnO}_{2} \mathrm{NPs}$ toward $\mathrm{H}_{2} \mathrm{O}_{2}$ was determined by ultraviolet-visible (UV-vis) absorption before and after $1 \mathrm{~h}$ incubation. $\mathrm{MnO}_{2}$ absorbs at $360 \mathrm{~nm}$, while $\mathrm{Mn}^{2+}$ ions has no absorption in the UV-vis region. After $1 \mathrm{~h}$ incubation, Man-HA- $\mathrm{MnO}_{2} \mathrm{NPs}$ were completely consumed by $\mathrm{H}_{2} \mathrm{O}_{2}$ released from macrophages, and enhanced $T_{1}$ and $T_{2}$ contrasts were observed (Figure S9).

Typically, MRI contrast agents are "always on" and not capable of highlighting biological events of interest because of a relatively low target-to-background contrast. However, the relaxivity of activatable MRI contrast agents varies in response to the change in the surrounding physiological microenvironment, potentially allowing MRI to sense biochemical activities. Activatable MRI contrast agents are typically designed using complexes to shield the paramagnetic ions from water molecules. The contrast enhancement after stimulation is of critical importance in evaluating the efficiency of an activatable MRI contrast agent. However, because of poor shielding efficiency, most activatable probes usually exhibit only modest contrast enhancement under stimuli and, ${ }^{34,35}$ thus, fail to be applied in the clinic. In the present study, Man-HA- $\mathrm{MnO}_{2} \mathrm{NP}$ as a $\mathrm{H}_{2} \mathrm{O}_{2}$-active MRI contrast agent showed 64- and 109-fold enhancement in $r_{1}$ and $r_{2}$ relaxivities, respectively (Figure S4). Such an ultrasensitive $T_{1}$ and $T_{2}$ MRI performance makes Man-HA-MnO $\mathrm{M}_{2} \mathrm{NPs}$ suitable as a contrast agent for MRI in vivo.

\section{Man-HA- $\mathrm{MnO}_{2}$ NPs Alleviate Tumor Hypoxia}

The effect of Man-HA-MnO ${ }_{2}$ NPs on tumor oxygenation was assessed using blood oxygen level-dependent (BOLD) MRI. BOLD MRI has been extensively used in studying brain function. ${ }^{36,37}$ It is now increasingly applied to noninvasively assess blood oxygenation and vascular function in tumors. ${ }^{38-40}$ The underlying rationale is that the paramagnetic deoxyhemoglobin creates microscopic field gradients, which enhance the transverse relaxation rate, $R_{2} *$, of water protons in blood and in the tissue adjacent to blood vessels. Decrease in deoxyhemoglobin concentration leads to a decreased $R_{2}{ }^{*}$, and thus, an increased signal intensity (SI) in $T_{2}{ }^{*}$-weighted MRI. We performed BOLD MRI on 4T1 tumor mice before, 3 and 7 days after iv injection of $13.2 \mathrm{mg} / \mathrm{kg}$ Man-HA- $\mathrm{MnO}_{2} \mathrm{NPs}$ or saline and observed a significant increase in $T_{2}^{*}$ values of tumors treated with Man-HA$\mathrm{MnO}_{2} \mathrm{NPs}$ up to $29.8 \%$ and $58.6 \%$ on day 3 and day 7, respectively (Figure 6), indicating increased $\mathrm{O}_{2}$ concentration in the tumor blood. Furthermore, the significant increase in $T_{2}{ }^{*}$ value of tumor was not only in the peripheral region, but also in the tumor core in which hypoxic region is located. On the contrary, the $T_{2}{ }^{*}$ values of tumors treated with saline were decreased on day 3 and day 7 . The advantage of using Man-HA-MnO${ }_{2} \mathrm{NPs}$ is the ability to 
increase $\mathrm{O}_{2}$ concentration in the tumor area by targeted delivery of Man-HA- $\mathrm{MnO}_{2}$ NPs to TAMs which are highly accumulated in tumor hypoxic region.

The increased $\mathrm{O}_{2}$ concentration in the tumor blood could be attributed to the reaction of Man-HA- $\mathrm{MnO}_{2}$ NPs toward $\mathrm{H}_{2} \mathrm{O}_{2}$ released by TAMs under acidic condition, which resulted in the $\mathrm{O}_{2}$ release. In addition, the effect of Man-HA- $\mathrm{MnO}_{2}$ NPs on macrophage polarization may also modulate tumor microenvironment. The improvement of the blood $\mathrm{O}_{2}$ concentration in tumors by Man-HA- $\mathrm{MnO}_{2}$ NPs would be a promising strategy to improve tumor physiology and alleviate tumor hypoxia. Furthermore, by combining such strategy with conventional anticancer treatments it may be possible to bring cancer growth, invasion, and metastasis to a halt.

We investigated the effect of Man-HA- $\mathrm{MnO}_{2}$ NPs on tumor hypoxia in vivo 4 days post-NPinjection by immunofluorescence staining to determine tissue hypoxia using a Pimonidazole marker ${ }^{41}$ and the expression of HIF-1 $a$ and VEGF using antibodies. The tumor showed $50.3 \%$ less tissue hypoxia, $49.3 \%$ decrease in the expression of HIF- $1 a$, and $31.8 \%$ decrease in the expression of VEGF 4 days after treatment with $13.2 \mathrm{mg} / \mathrm{kg}$ Man-HA- $\mathrm{MnO}_{2} \mathrm{NPs}$ compared to those in saline treatment group (Figure 7), indicating the ability of Man-HA$\mathrm{MnO}_{2}$ NPs to reduce tumor hypoxia. HIF- $1 a$ produced by tumor cells plays a pivotal role in adaptive response to hypoxia by modulating various cellular functions like proliferation, apoptosis, angiogenesis and anaerobic glycolysis. ${ }^{42,43}$ Upon activation, HIF-1 $a$ binds to the hypoxia responsive element, thereby promoting transcription of various genes including VEGF. The expression of VEGF further induces angiogenesis and plays a key role in promoting malignant tumor growth. ${ }^{44}$ Thus, downregulation of HIF-1 $a$ and VEGF expression by alleviating tumor hypoxia would inhibit tumor progression.

To account for significant reduction of tumor hypoxia, several factors were considered as the following: (1) Man-HA-MnO${ }_{2}$ NPs could be successfully delivered to tumor hypoxia by TAM accumulation, which would allow the reaction of Man-HA- $\mathrm{MnO}_{2} \mathrm{NPs}$ toward $\mathrm{H}_{2} \mathrm{O}_{2}$ in the hypoxic region of the tumor and large amount of $\mathrm{O}_{2}$ release; (2) Man- $\mathrm{HA}-\mathrm{MnO}_{2} \mathrm{NPs}$ can successfully skew TAMs away from the M2 phenotype to a tumor-inhibiting M1 phenotype, which would provide an opportunity to alleviate tumor hypoxia and downregulate HIF-1 $a$ and VEGF expression, since TAMs are known to accumulate in large numbers in the hypoxic regions of solid tumors and cooperate with tumor cells to upregulate HIF-1 $a$, VEGF and MMP-7 expression, promoting tumor proliferation. (3) The improved tumor $\mathrm{O}_{2}$ level by reaction of Man-HA- $\mathrm{MnO}_{2}$ NPs with $\mathrm{H}_{2} \mathrm{O}_{2}$ would efficiently manipulate the tumor microenvironment.

\section{Man-HA- $\mathrm{MnO}_{2}$ NPs Enhance Chemotherapy Response}

Several studies have shown that tumor cells in hypoxic region are more resistant to chemotherapy than those with normal levels of oxygen. To evaluate whether hypoxia reduction by Man-HA- $\mathrm{MnO}_{2} \mathrm{NPs}$ can enhance tumor chemotherapy, we conducted preliminary studies in 4T1 breast tumor model using diffusion-weighted MRI (DW-MRI). DWI is a well-studied MR imaging technique for quantifying the increase in water diffusion caused by cell necrosis or apoptosis in tumors within 2-4 days, prior to visible changes in tumor morphology or size ${ }^{45}$ With the use of DW-MRI, diffusion of water within tissue can 
be noninvasively quantified as an apparent diffusion coefficient (ADC). Shift of ADC histogram to a higher ADC value can be an early and quantifiable indicator of therapeutic efficacy. ${ }^{46}$ We treated mice bearing $4 \mathrm{~T} 1$ tumors with $13.2 \mathrm{mg} / \mathrm{kg}$ Man-HA- $\mathrm{MnO}_{2} \mathrm{NPs}$ or saline $6 \mathrm{~h}$ prior to doxorubicin (Dox) administration. DW-MRI was performed before, day 2 and day 4 post-treatment. The significant increase in ADC values was observed in mice treated with combined Man-HA-MnO${ }_{2}$ NPs and Dox up to $35.6 \%$ and $42 \%$ at day 2 and day 4 , respectively, compared to the control group. We also observed a significant tumor growth delay in the combined Man-HA- $\mathrm{MnO}_{2} \mathrm{NP}$ and Dox treatment group compared to the control group. The average tumor volume after the combination therapy averaged $78 \mathrm{~mm}^{3}$, while the Dox alone group reached an average tumor volume of $143 \mathrm{~mm}^{3}$ at day 9 . Interestingly, an increase in ADC value was also observed in the Man-HA- $\mathrm{MnO}_{2}$ NPs alone group compared to the saline group (Figure 8A). The antitumor effect of Man-HA-MnO $\mathrm{NPs}_{2}$ may be caused by TAM phenotype switching and the manipulation of the tumor microenvironment by ManHA- $\mathrm{MnO}_{2} \mathrm{NPs}$, since the cytotoxicity of M1 macrophages contributes to tumor killing by releasing $\mathrm{NO}, \mathrm{H}_{2} \mathrm{O}_{2}$, peroxynitrite and superoxide. To confirm the effect of Man-HA- $\mathrm{MnO}_{2}$ NPs on enhancement of chemotherapy response, tumor cell proliferation was determined by immunofluorescence staining with proliferating cell nuclear antigen (PCNA) antibody. A significant decrease in PCNA expression was observed in the combination of Man-HA$\mathrm{MnO}_{2}$ NPs with Dox and Man-HA-MnO 2 NPs alone treatment up to $67.2 \%$ and $28.4 \%$, respectively, compared to that of saline control. Dox also had effect on tumor cell proliferation but was not as strong as the combined Man-HA-MnO $\mathrm{O}_{2} \mathrm{NPs}$ and Dox treatment (Figure 7). A MTT assay was employed to determine the ability of Man-HA-MnO ${ }_{2}$ NPs to enhance chemotherapy response in vitro. 4T1 tumor cells were cocultured with RAW 264.7 macrophages for $24 \mathrm{~h}$, then treated with different concentrations of Dox $(0-0.6 \mu \mathrm{g} / \mathrm{mL})$ or the combination of $5 \mu \mathrm{M}$ Man-HA- $\mathrm{MnO}_{2} \mathrm{NPs}$ and Dox for $24 \mathrm{~h}$. The combination therapy had a higher tumor inhibition effect than Dox alone, and the $\mathrm{IC}_{50}$ values were 0.11 and 0.31 $\mu \mathrm{g} / \mathrm{mL}$, respectively $(P=0.02)$. There was a significant reduction in cell viability in the group treated with combination of Man-HA-MnO 2 NPs and Dox when the Dox concentrations were as low as $0.3-1 \mu \mathrm{g} / \mathrm{mL}$ (Figure $\mathrm{S} 10$ ).

The reduction of tumor hypoxia by Man-HA- $\mathrm{MnO}_{2} \mathrm{NPs}$ could contribute to the enhancement of chemotherapy response, as we observed $64.5 \%$ less tissue hypoxia, $62.7 \%$ decrease in the expression of HIF- $1 a$, and $39.7 \%$ decrease in the expression of VEGF 4 days after treatment with the combination of Man-HA- $\mathrm{MnO}_{2}$ NPs and Dox compared to those in the saline control group (Figure 7). Skewing TAM polarization away from the M2 phenotype to a tumor-inhibiting M1 phenotype by Man-HA- $\mathrm{MnO}_{2}$ NPs may also be a factor contributing to the enhancement of chemotherapy response. Since evidence has been provided that TAMs may be also associated with chemoresistance of cancer, ${ }^{14,15}$ Man-HA$\mathrm{MnO}_{2}$ NPs would be a promising adjuvant to cancer chemotherapeutics by improving tumor

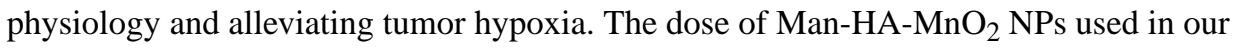
study was relatively high, for translation of this strategy into clinic, further modifications to optimize the performance of such nanoparticle platform are warranted in the future studies. 


\section{CONCLUSION}

Targeted delivery of HA modified $\mathrm{MnO}_{2}$ nanoparticles (Man-HA-MnO 2 NPs) to TAMs can successfully alleviate tumor hypoxia and enhance chemotherapy response by tilting TAM polarization from the M2 phenotype to a tumor-inhibiting M1 phenotype and improving tumor oxygen level by reacting with endogenous $\mathrm{H}_{2} \mathrm{O}_{2}$ under hypoxic conditions. In addition, the released $\mathrm{Mn}^{2+}$ ions have the ability to highly enhance $T_{1}$ MRI performance for tumor imaging and detection.

\section{METHODS}

\section{Nanoparticle Synthesis}

$\mathrm{MnO}_{2} \mathrm{NPs}$ were prepared by directly mixing the aqueous solutions of $\mathrm{KMnO}_{4}$ and poly(allylamine hydrochloride) (PAH, $15 \mathrm{kDa}$ ). Briefly, $18 \mathrm{~mL}$ of $\mathrm{KMnO}_{4}$ solution $(3.5 \mathrm{mg}$ $\mathrm{mL}^{-1}$ ) was mixed with $2 \mathrm{~mL}$ of PAH solution $\left(37.4 \mathrm{mg} \mathrm{mL}^{-1}\right)$, and the mixture was left for $15 \mathrm{~min}$ at room temperature until all permanganate was converted to $\mathrm{MnO}_{2}$. NP formation was confirmed by recording UV-vis absorption spectrum. NPs were washed three times with doubly distilled (DDI) water using ultracentrifugation (50 k rpm for $1 \mathrm{~h}$ ). This step led to small $(\sim 15 \mathrm{~nm}) \mathrm{MnO}_{2}$ NPs stabilized with PAH. The $\mathrm{MnO}_{2}$ NPs were conjugated to the HA backbone by a condensation reaction. Briefly, $100 \mathrm{mg}$ HA (40 kDa molecular weight) was dissolved in distilled water $(20 \mathrm{~mL})$. Then, the HA was activated under stirring for 30 min in the presence of 1-ethyl-3-(3-(dimethylamino)propyl)-carbodiimide (EDC, 0.64 $\mathrm{mmol}$ ) and $\mathrm{N}$-hydroxysuccinimide (NHS, $0.64 \mathrm{mmol}$ ). Then, the $\mathrm{MnO}_{2} \mathrm{NPs}$ were added dropwise at various $\mathrm{HA} / \mathrm{MnO}_{2} \mathrm{NP}$ weight ratios $(\mathrm{w} / \mathrm{w})$ and reacted with activated carboxylic ester of HA under stirring at $35{ }^{\circ} \mathrm{C}$ for $3 \mathrm{~h}$. The $\mathrm{HA}-\mathrm{MnO}_{2} \mathrm{NPs}$ were purified three times with DDI water using centrifugation ( $12 \mathrm{k} \mathrm{rpm}$ for $30 \mathrm{~min}$ ). Mannan-PE was synthesized in accordance with the method described. ${ }^{47}$ Surface modification of $\mathrm{HA}-\mathrm{MnO}_{2} \mathrm{NPs}$ with mannan-PE ligands was accomplished according to the procedure developed by Yu et al. ${ }^{47}$ The total ligand-to-carrier weight ratio was optimized by measuring the change in zeta potential. The optimum ratio occurred when increasing the ligand-to-carrier weight ratio led to no significant change in zeta potential.

\section{Cell Association and Cellular Uptake of NPs}

M1 and M2 macrophages were generated by pretreating RAW264.7 cells with $1 \mu \mathrm{g} / \mathrm{mL}$ LPS or $25 \mathrm{ng} / \mathrm{mL}$ IL-4 (eBioscience) for $24 \mathrm{~h}$, respectively. M2 macrophages $\left(10^{5}\right.$ cells $/ \mathrm{mL}$ ) were incubated for $1 \mathrm{~h}$ with fluorescent dye Cy5.5 labeled Man-HA-MnO${ }_{2}$ NPs or $\mathrm{HA}-\mathrm{MnO}_{2} \mathrm{NPs}$ $(4 \mu \mathrm{M} \mathrm{Mn})$ at 4 or $37^{\circ} \mathrm{C}$ before microscopy and flow cytometry analysis. Confocal microscope (Olympus, USA) and flow cytometer (Beckman Coulter, USA) were used to image and quantify positive cells following incubation with fluorescent dye labeled NPs. Cell nuclei were stained blue with DAPI (Invitrogen Molecular Probes, USA).

\section{Quenching of $\mathrm{H}_{2} \mathrm{O}_{2}$ by NPs}

For the quenching experiment, Man-HA- $\mathrm{MnO}_{2} \mathrm{NPs}$ or $\mathrm{MnO}_{2} \mathrm{NPs}(50 \mu \mathrm{M} \mathrm{Mn})$ was placed in phosphate buffer at $\mathrm{pH} 6.5$, and $\mathrm{H}_{2} \mathrm{O}_{2}(300 \mu \mathrm{M})$ was added to initiate the reaction. For in vitro reactivity of Man-HA- $\mathrm{MnO}_{2} \mathrm{NPs}$ toward $\mathrm{H}_{2} \mathrm{O}_{2}$, RAW264.7 cells were pretreated with 
$25 \mathrm{ng} / \mathrm{mL}$ IL-4 to generate M2 macrophages, then incubated with $5 \mu \mathrm{M}$ Man-HA-MnO${ }_{2} \mathrm{NPs}$ or $\mathrm{HA}-\mathrm{MnO}_{2} \mathrm{NPs}$ at $\mathrm{pH}$ 6.8. The residual amount of $\mathrm{H}_{2} \mathrm{O}_{2}$ was determined over time using a PeroXOquant assay kit (Pierce, USA), and change of $\mathrm{pH}$ was measured with a $\mathrm{pH}$ meter (PHS, China). $T_{1}$ - and $T_{2}$-weighted MRI contrast signals were determined by MRI.

\section{MRI}

MRI experiments were performed on a Bruker Biospin 9.4T animal MRI scanner (Bruker, Germany) equipped with a horizontal bore (diameter, $30 \mathrm{~cm}$; gradient strength, $734 \mathrm{mT} / \mathrm{m}$ ). For accurate tumor imaging, $T_{2}$-weighted images were obtained using a spin echo multiple slice sequence with a repetition time (TR) of $2500 \mathrm{~ms}$ and an effective echo time (TE) of 33 ms.

The $T_{1}$ relaxation time was estimated using a spin echo multiple slice sequence at variable TR values; eight TR values of 327.1-5500 ms were used and TE was $11 \mathrm{~ms}$. The $T_{2}$ relaxation time was measured using a multislice multiecho technique with a TR of $2500 \mathrm{~ms}$ and $16 \mathrm{TE}$ of $11-176 \mathrm{~ms}$. The $T_{2} *$ relaxation time was measured using a multigradient echo technique with a TR of $1500 \mathrm{~ms}, 12 \mathrm{TE}$ values of $3.8-45 \mathrm{~ms}$, and a flip angle of $30^{\circ}$.

DW-MRI was used with the following parameters: TR $=2700 \mathrm{~ms}$; TE $=27 \mathrm{~ms}$; matrix $=256$ $\times 256$; multislice spin-echo sequence with field of view of $30 \times 30 \mathrm{~mm}$ at $b=0$ and 800 $\mathrm{s} / \mathrm{mm}^{2}$. The gradients were applied in three orthogonal directions.

\section{Optical Imaging}

A Xenogen IVIS Spectrum Imaging System (Caliper Life Sciences Inc., USA) was used to image tumor bearing animals over time following iv treatment with near-infrared labeled $13.2 \mathrm{mg} / \mathrm{kg}$ Man-HA-MnO 2 NPs. At each time point, a bright field image was acquired and fluorescence of labeled Man-HA- $\mathrm{MnO}_{2} \mathrm{NPs}$ was imaged at $680 \mathrm{~nm}$ excitation and $745 \mathrm{~nm}$ emission. At $24 \mathrm{~h}$ postinjection, tumors and major organs were excised for ex vivo NIRF imaging to determine the tissue distribution of Man-HA- $\mathrm{MnO}_{2} \mathrm{NPs}$. All main organs were cut with similar thickness and imaged at $680 \mathrm{~nm}$ excitation and $745 \mathrm{~nm}$ emission. The average fluorescence intensity of organs was from a region of interest (ROI) placed over the area of the organs on the image.

\section{Immunohistochemistry}

At predetermined time points, animals were sacrificed and tumor tissues were harvested, embedded in OCT medium, and snap frozen. Six-micrometer sections were cut and fixed in $10 \%$ paraformaldehyde solution, followed by immunostaining with the primary antibody. Primary antibody was detected by sequential incubation with secondary antibody (goat antirabbit immunoglobulin G conjugated to FITC or Cy5, Life Technologies, New York, NY, USA). Slides were scanned with Confocal microscope (Olympus, USA) and images were analyzed with ImageJ 7.0 software.

To evaluate tumor hypoxia, the hypoxia marker Pimonidazole hydrochloride (Hypoxyprobe-1 plus kit, Hypoxyprobe, Inc., USA) was used for ex vivo tissue staining of hypoxia following the protocol provided with the kit. Rabbit polyclonoal HIF-1 $a$ antibody 
(dilution 1:100, Novus Biologicals, catalog number NB100-134) and rabbit anti-VEGF antibody (dilution 1:100, Thermo Scientific, catalog number ab-222-P) as the primary antibody were used for the staining of HIF-1 $a$ and VEGF, respectively. To evaluate the effect of Man-HA- $\mathrm{MnO}_{2}$ NPs on the polarization of TAMs, rabbit polyclonal CD206 antibody (dilution 1:200, abcam, catalog number ab64693) and rabbit polyclonal iNOS antibody (dilution 1:200, abcam, catalog number ab3523) as the primary antibody were used to determine the distribution of M2 and M1 macrophages, respectively. To confirm the effect of Man-HA- $\mathrm{MnO}_{2}$ NPs on enhancement of chemotherapy response, tumor cell proliferation was determined by immunofluorescence staining with rabbit polyclonal PCNA antibody (1:200, abcam, catalog number ab18197).

\section{Flow Cytometry}

Tumors were mechanically disrupted, and incubated in $1 \%$ collagenase type IV diluted in RPMI 1640 medium with $1 \% \mathrm{BSA}$ for $1 \mathrm{~h}$ at $37^{\circ} \mathrm{C}$. Collagenase activity was stopped by adding an equal volume of Dulbecco Modified Eagle's medium (DMEM) supplemented with $10 \%$ fetal bovine serum (FBS) followed by centrifugation at $300 \mathrm{~g}$ for $10 \mathrm{~min}$. Cell pellets were filtered through $100 \mu \mathrm{m}$ nylon mesh cell strainer. Cultured cells were collected following the standard procedure. Samples from tumors and cells were incubated with rabbit polyclonal CD206 antibody (dilution 1:200, abcam, catalog number ab64693) and rabbit polyclonal iNOS antibody (dilution 1:200, abcam, catalog number ab3523) to label M2 and M1 macrophages. Primary antibody was detected by sequential incubation with secondary antibody (goat anti-rabbit immunoglobulin G conjugated to FITC or Cy5 (Life Technologies, New York, NY, USA). Isotype controls were employed to establish background fluorescence. Data were acquired on a Beckman Coulter Gallios (Beckman Coulter, USA) and analyzed by FlowJo software (Tree Star, San Carlos, CA, USA)

\section{Quantification of IL-10 and IL-12 Levels}

To determine the IL-10 and IL-12 levels in cells, the cells were lysed in $1 \mathrm{~mL}$ of RIPA buffer as a lysis buffer, maintained at $4{ }^{\circ} \mathrm{C}$ for $3 \mathrm{~h}$, and centrifuged at $14000 \mathrm{rpm}$ and $4{ }^{\circ} \mathrm{C}$ for 15 $\min$. The total protein concentration in the supernatant was determined by the BCA protein assay. The IL-10 and IL-12 concentration in the supernatant was analyzed with mouse IL-10 and IL-12 ELISA kits (Thermo Scientific).

\section{Quantification of Mn Accumulated in the Tissue}

The mice were sacrificed and most of the blood was flushed out. The dissected organ samples were dried and weighed. The Mn content was determined by ICP-MS. The organ samples were dissolved in $5 \mathrm{~mL}$ of freshly prepared aqua regia with heating until the solution became transparent. After evaporation, $1 \mathrm{~mL}$ of $50 \% \mathrm{HCl}$ and $1 \mathrm{~mL}$ of $50 \% \mathrm{HNO}_{3}$ were added and diluted to a final volume of $10 \mathrm{~mL}$ with water. The samples were analyzed by ICP-MS (Thermo Fischer Scientific iCAP-QC).

\section{Chemotherapy}

4T1 murine breast cancer model was established by subcutaneous injection of $10^{6}$ cells $/ \mathrm{mL}$ 4T1 cells into the flank of Balb/c female mice. Mice were divided into four groups ( $n=6 /$ 
group): (1) saline, (2) Dox (5 mg/kg), (3) Man-HA-MnO 2 NP (13.2 mg/kg), (4) Man-HA$\mathrm{MnO}_{2} \mathrm{NP}(13.2 \mathrm{mg} / \mathrm{kg})+$ Dox $(5 \mathrm{mg} / \mathrm{kg})$. Treatments were initiated when the tumors reached an approximate volume of $118 \mathrm{~mm}^{3}$. The mice were iv pretreated with $13.2 \mathrm{mg} / \mathrm{kg}$ Man-HA-MnO $\mathrm{O}_{2} \mathrm{NP} 6 \mathrm{~h}$ before $5 \mathrm{mg} / \mathrm{kg}$ Dox administration. DW-MRI was performed on day 0,2 , and 4 after treatment. The tumor size was measured as a function of time with vernier calipers in two dimensions and tumor volumes were calculated by the formula $V=$ $\left[\right.$ (length) $\left.\times(\text { width })^{2}\right] / 2$. At the end of experiment, the animals were sacrificed and the tumor masses were excised. Tumor tissue was subjected to histological analysis to determine tumor cell proliferation. The experimental design was approved by the Xiamen University Committee on the Use and Care of Animals.

A MTT assay was employed to determine the ability of Man-HA- $\mathrm{MnO}_{2}$ NPs to enhance chemotherapy response in vitro. 4T1 tumor cells were cocultured with RAW 264.7 macrophages (3:1) for $24 \mathrm{~h}$, then treated with different concentrations of Dox $(0-0.6 \mu \mathrm{g} / \mathrm{mL})$

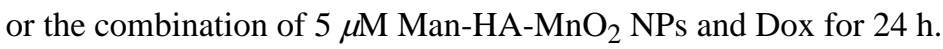

\section{Statistical Analysis}

Data are presented as mean \pm standard error of the mean for results obtained from three independent trials unless otherwise indicated. Student's $t$ test or analysis of variance (ANOVA) (OriginPro8) was utilized to determine statistical significance between two or more groups, respectively. $P$-values $<0.05$ were considered statistically significant.

\section{Supplementary Material}

Refer to Web version on PubMed Central for supplementary material.

\section{ACKNOWLEDGMENTS}

This research was supported by the National Science Foundation of China (81501533), National Key Basic Research Program of China (2014CB744503), and the Intramural Research Program, National Institute of Biomedical Imaging and Bioengineering, National Institutes of Health.

\section{REFERENCES}

(1). Gatenby RA, Gillies RJ. A Microenvironmental Model of Carcinogenesis. Nat. Rev. Cancer. 2008; 8:56-61. [PubMed: 18059462]

(2). Bertout JA, Patel SA, Simon MC. The Impact of $\mathrm{O}_{2}$ Availability on Human Cancer. Nat. Rev. Cancer. 2008; 8:967-975. [PubMed: 18987634]

(3). Eubank TD, Roberts RD, Khan M, Curry JM, Nuovo GJ, Kuppusamy P, Marsh CB. Granulocyte Macrophage Colony-Stimulating Factor Inhibits Breast Cancer Growth and Metastasis by Invoking an Anti-Angiogenic Program in Tumor-Educated Macrophages. Cancer Res. 2009; 69:2133-2140. [PubMed: 19223554]

(4). Mehlen P, Puisieux A. Metastasis: A Question of Life or Death. Nat. Rev. Cancer. 2006; 6:449_ 458. [PubMed: 16723991]

(5). Wu W, Yang Q, Li T, Zhang P, Zhou R, Yang C. Hemoglobin-Based Oxygen Carriers Combined with Anticancer Drugs May Enhance Sensitivity of Radiotherapy and Chemotherapy to Solid Tumors. Artif. Cells Blood Substit. Immobil. Biotechnol. 2009; 37:163-165. [PubMed: 19548133]

(6). Janssens GO, Rademakers SE, Terhaard CH, Doornaert PA, Bijl HP, van den Ende P, Chin A, Marres HA, de Bree R, van der Kogel AJ, et al. Accelerated Radiotherapy with Carbogen and 
Nicotinamide for Laryngeal Cancer: Results of a Phase III Randomized Trial. J. Clin. Oncol. 2012; 30:1777-1783. [PubMed: 22508814]

(7). Zannella VE, Dal Pra A, Muaddi H, McKee TD, Stapleton S, Sykes J, Glicksman R, Chaib S, Zamiara P, Milosevic M, et al. Reprogramming Metabolism with Metformin Improves Tumor Oxygenation and Radiotherapy Response. Clin. Cancer Res. 2013; 19:6741-6750. [PubMed: 24141625]

(8). Murdoch C, Giannoudis A, Lewis CE. Mechanisms Regulating the Recruitment of Macrophages into Hypoxic Areas of Tumors and other Ischemic Tissues. Blood. 2004; 104:2224-2234. [PubMed: 15231578]

(9). Casazza A, Laoui D, Wenes M, Rizzolio S, Bassani N, Mambretti M, Deschoemaeker S, Van Ginderachter JA, Tamagnone L, Mazzone M. Impeding Macrophage Entry into Hypoxic Tumor Areas by Sema3A/Nrp1 Signaling Blockade Inhibits Angiogenesis and Restores Antitumor Immunity. Cancer Cell. 2013; 24:695-709. [PubMed: 24332039]

(10). Martinez FO, Sica A, Mantovani A, Locati M. Macrophage Activation and Polarization. Front. Biosci., Landmark Ed. 2008; 13:453-461.

(11). Hao NB, Lu MH, Fan YH, Cao YL, Zhang ZR, Yang SM. Macrophages in Tumor Microenvironments and the Progression of Tumors. Clin. Dev. Immunol. 2012; 2012:948098. [PubMed: 22778768]

(12). Solinas G, Germano G, Mantovani A, Allavena P. Tumor-Associated Macrophages (TAM) as Major Players of the Cancer-Related Inflammation. J. Leukocyte Biol. 2009; 86:1065-1073. [PubMed: 19741157]

(13). Laoui D, Van Overmeire E, Di Conza G, Aldeni C, Keirsse J, Morias Y, Movahedi K, Houbracken I, Schouppe E, Elkrim Y, et al. Tumor Hypoxia does not Drive Differentiation of Tumor-Associated Macrophages but rather Fine-Tunes the M2-Like Macrophage Population. Cancer Res. 2014; 74:24-30. [PubMed: 24220244]

(14). Yang C, He L, He P, Liu Y, Wang W, He Y, Du Y, Gao F. Increased Drug Resistance in Breast Cancer by Tumor-Associated Macrophages through IL-10/STAT3/Bcl-2 Signaling Pathway. Med. Oncol. 2015; 32:352. [PubMed: 25572805]

(15). Jinushi M, Chiba S, Yoshiyama H, Masutomi K, Kinoshita I, Dosaka-Akita H, Yagita H, Takaoka A, Tahara H. Tumor-Associated Macrophages Regulate Tumorigenicity and Anticancer Drug Responses of Cancer Stem/Initiating Cells. Proc. Natl. Acad. Sci. U. S. A. 2011; 108:1242512430. [PubMed: 21746895]

(16). Griffiths L, Binley K, Iqball S, Kan O, Maxwell P, Ratcliffe P, Lewis C, Harris A, Kingsman S, Naylor S. The Macrophage - A Novel System to Deliver Gene Therapy to Pathological Hypoxia. Gene Ther. 2000; 7:255-262. [PubMed: 10694803]

(17). Shiri S, Alizadeh AM, Baradaran B, Farhanghi B, Shanehbandi D, Khodayari S, Khodayari H, Tavassoli A. Dendrosomal Curcumin Suppresses Metastatic Breast Cancer in Mice by Changing M1/M2Macrophage Balance in the Tumor Microenvironment. Asian Pac. J. Cancer Prev. 2015; 16:3917-3922. [PubMed: 25987060]

(18). Luo XL, Xu JJ, Zhao W, Chen HY. A Novel Glucose ENFET Based on the Special Reactivity of $\mathrm{MnO}_{2}$ Nanoparticles. Biosens. Bioelectron. 2004; 19:1295-1300. [PubMed: 15046762]

(19). Prasad P, Gordijo CR, Abbasi AZ, Maeda A, Ip A, Rauth AM, DaCosta RS, Wu XY. Multifunctional Albumin- $\mathrm{MnO}_{2}$ Nanoparticles Modulate Solid Tumor Microenvironment by Attenuating Hypoxia, Acidosis, Vascular Endothelial Growth Factor and Enhance Radiation Response. ACS Nano. 2014; 8:3202-3212. [PubMed: 24702320]

(20). Rayahin JE, Buhrman JS, Zhang Y, Koh TJ, Gemeinhart RA. High and Low Molecular Weight Hyaluronic Acid Differentially Influence Macrophage Activation. ACS Biomater. Sci. Eng. 2015; 1:481-493. [PubMed: 26280020]

(21). Lyle DB, Breger JC, Baeva LF, Shallcross JC, Durfor CN, Wang NS, Langone JJ. Low Molecular Weight Hyaluronic Acid Effects on Murine Macrophage Nitric Oxide Production. J. Biomed. Mater. Res., Part A. 2010; 94:893-904.

(22). Aoki I, Takahashi Y, Chuang KH, Silva AC, Igarashi T, Tanaka C, Childs RW, Koretsky AP. Cell Labeling for Magnetic Resonance Imaging with the T1 Agent Manganese Chloride. NMR Biomed. 2006; 19:50-59. [PubMed: 16411253] 
(23). Loving GS, Mukherjee S, Caravan P. Redox-Activated Manganese-Based MR Contrast Agent. J. Am. Chem. Soc. 2013; 135:4620-4623. [PubMed: 23510406]

(24). Troughton JS, Greenfield MT, Greenwood JM, Dumas S, Wiethoff AJ, Wang J, Spiller M, McMurry TJ, Caravan P. Synthesis and Evaluation of a High Relaxivity Manganese(II)-Based MRI Contrast Agent. Inorg. Chem. 2004; 43:6313-6323. [PubMed: 15446878]

(25). Na HB, Lee JH, An K, Park YI, Park M, Lee IS, Nam DH, Kim ST, Kim SH, Kim SW, et al. Development of a T1 Contrast Agent for Magnetic Resonance Imaging Using MnO Nanoparticles. Angew. Chem., Int. Ed. 2007; 46:5397-5401.

(26). Viger ML, Sankaranarayanan J, de Gracia Lux C, Chan M, Almutairi A. Collective Activation of MRI Agents via Encapsulation and Disease-Triggered Release. J. Am. Chem. Soc. 2013; 135:7847-7850. [PubMed: 23672342]

(27). Movahedi K, Schoonooghe S, Laoui D, Houbracken I, Waelput W, Breckpot K, Bouwens L, Lahoutte T, De Baetselier P, Raes G, et al. Nanobody-Based Targeting of the Macrophage Mannose Receptor for Effective In Vivo Imaging of Tumor-Associated Macrophages. Cancer Res. 2012; 72:4165-4177. [PubMed: 22719068]

(28). Zhao Z, Fan H, Zhou G, Bai H, Liang H, Wang R, Zhang X, Tan W. Activatable Fluorescence/MRI Bimodal Platform for Tumor Cell Imaging via $\mathrm{MnO}_{2}$ Nanosheet-Aptamer Nanoprobe. J. Am. Chem. Soc. 2014; 136:11220-11223. [PubMed: 25061849]

(29). Pan D, Schmieder AH, Wickline SA, Lanza GM. Manganese-Based MRI Contrast Agents: Past, Present and Future. Tetrahedron. 2011; 67:8431-8444. [PubMed: 22043109]

(30). Pan D, Caruthers SD, Senpan A, Schmieder AH, Wickline SA, Lanza GM. Revisiting an Old Friend: Manganese-Based MRI Contrast Agents. Wiley Interdiscip. Rev. Nanomed. Nanobiotechnol. 2011; 3:162-173. [PubMed: 20860051]

(31). Martinez FO, Gordon S, Locati M, Mantovani A. Transcriptional Profiling of the Human Monocyte-to-Macrophage Differentiation and Polarization: New Molecules and Patterns of Gene Expression. J. Immunol. 2006; 177:7303-7311. [PubMed: 17082649]

(32). Scheibner KA, Lutz MA, Boodoo S, Fenton MJ, Powell JD, Horton MR. Hyaluronan Fragments Act as an Endogenous Danger Signal by Engaging TLR2. J. Immunol. 2006; 177:1272-1281. [PubMed: 16818787]

(33). Black KE, Collins SL, Hagan RS, Hamblin MJ, Chan-Li Y, Hallowell RW, Powell JD, Horton MR. Hyaluronan Fragments Induce IFN- $\beta$ via a Novel TLR4-TRIF-TBK1-IRF3-dependent pathway. J. Inflammation (London, U. K.). 2013; 10:23.

(34). Tu C, Nagao R, Louie AY. Multimodal Magnetic-Resonance/Optical-Imaging Contrast Agent Sensitive to NADH. Angew. Chem., Int. Ed. 2009; 48:6547-6551.

(35). Gianolio E, Maciocco L, Imperio D, Giovenzana GB, Simonelli F, Abbas K, Bisi G, Aime S. Dual MRI-SPECT Agent for pH-Mapping. Chem. Commun. (Cambridge, U. K.). 2011; 47:1539-1541.

(36). Hall CN, Reynell C, Gesslein B, Hamilton NB, Mishra A, Sutherland BA, O'Farrell FM, Buchan AM, Lauritzen M, Attwell D. Capillary Pericytes Regulate Cerebral Blood Flow in Health and Disease. Nature. 2014; 508:55-60. [PubMed: 24670647]

(37). Kami A, Meyer G, Jezzard P, Adams MM, Turner R, Ungerleider LG. Functional MRI Evidence for Adult Motor Cortex Plasticity During Motor Skill Learning. Nature. 1995; 377:155-158. [PubMed: 7675082]

(38). Zhao D, Pacheco-Torres J, Hallac RR, White D, Peschke P, Cerdan S, Mason RP. Dynamic Oxygen Challenge Evaluated by NMR T1 and T2* - Insights into Tumor Oxygenation. NMR Biomed. 2015; 28:937-947. [PubMed: 26058575]

(39). Kim CK, Park SY, Park BK, Park W, Huh SJ. Blood Oxygenation Level-Dependent MR Imaging as a Predictor of Therapeutic Response to Concurrent Chemoradiotherapy in Cervical Cancer: A Preliminary Experience. Eur. Radiol. 2014; 24:1514-1520. [PubMed: 24763631]

(40). Jiang L, Weatherall PT, McColl RW, Tripathy D, Mason RP. Blood Oxygenation LevelDependent (BOLD) Contrast Magnetic Resonance Imaging (MRI) for Prediction of Breast Cancer Chemotherapy Response: A Pilot Study. J. Magn. Reson. Imaging. 2013; 37:1083-1092. [PubMed: 23124705] 
(41). Rademakers SE, Lok J, van der Kogel AJ, Bussink J, Kaanders JH. Metabolic Markers in Relation to Hypoxia; Staining Patterns and Colocalization of Pimonidazole, HIF-1alpha, CAIX, LDH-5, GLUT-1, MCT1 and MCT4. BMC Cancer. 2011; 11:167. [PubMed: 21569415]

(42). Denko NC. Hypoxia, HIF1 and Glucose Metabolism in the Solid Tumour. Nat. Rev. Cancer. 2008; 8:705-713. [PubMed: 19143055]

(43). Semenza GL. Targeting HIF-1 for Cancer Therapy. Nat. Rev. Cancer. 2003; 3:721-32. [PubMed: 13130303]

(44). Carmeliet P, Jain RK. Angiogenesis in Cancer and Other Diseases. Nature. 2000; 407:249-257. [PubMed: 11001068]

(45). Moffat BA, Hall DE, Stojanovska J, McConville PJ, Moody JB, Chenevert TL, Rehemtulla A, Ross BD. Diffusion Imaging for Evaluation of Tumor Therapies in Preclinical Animal Models. MAGMA. 2004; 17:249-259. [PubMed: 15580371]

(46). Jordan BF, Runquist M, Raghunand N, Baker A, Williams R, Kirkpatrick L, Powis G, Gillies RJ. Dynamic Contrast-Enhanced and Diffusion MRI Show Rapid and Dramatic Changes in Tumor Microenvironment in Response to Inhibition of HIF-1alpha Using PX-478. Neoplasia. 2005; 7:475-485. [PubMed: 15967100]

(47). Yu W, Liu C, Liu Y, Zhang N, Xu W. Mannan-Modified Solid Lipid Nanoparticles for Targeted Gene Delivery to Alveolar Macrophages. Pharm. Res. 2010; 27:1584-1596. [PubMed: 20422265] 
A
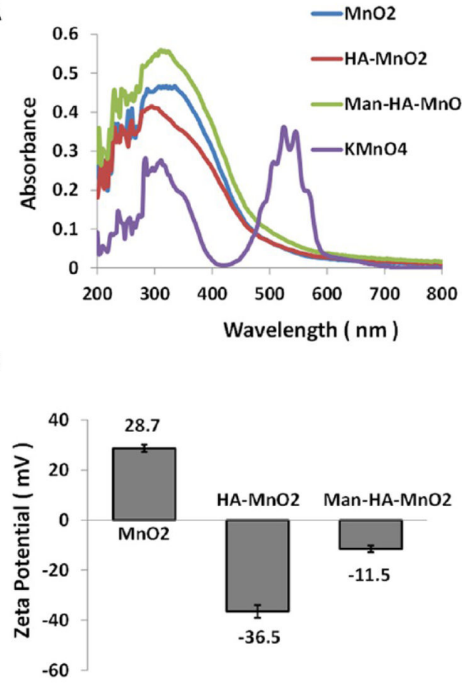

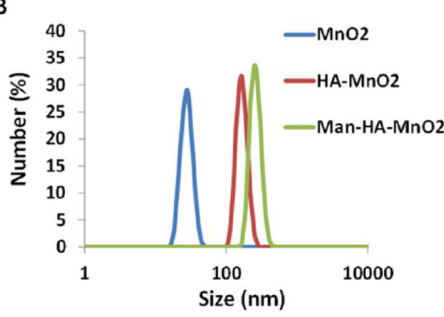

D

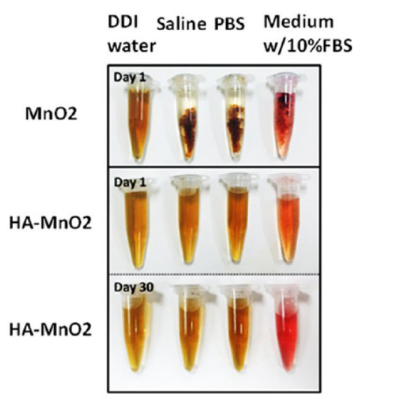

Figure 1.

Characterization of Man-HA-MnO 2 NPs: (A) UV-vis absorption spectra of $\mathrm{KMnO}_{4}$ solution, $\mathrm{MnO}_{2}$ NPs, HA- $\mathrm{MnO}_{2}$ NPs and Man-HA-MnO $\mathrm{MPs}_{2}$. After the reaction with PAH, the $\mathrm{KMnO}_{4}$ peaks $(315,525$, and $545 \mathrm{~nm})$ disappeared, and a new peak at $300 \mathrm{~nm}$ appeared, indicating the formation of $\mathrm{MnO}_{2}$ NPs. (B) Zeta potentials of $\mathrm{MnO}_{2} \mathrm{NPs}, \mathrm{HA}-\mathrm{MnO}_{2} \mathrm{NPs}$ and Man-HA-MnO 2 NPs. (C) Size distribution of different NPs. (D) Picture of $\mathrm{MnO}_{2} \mathrm{NPs}$ and Man-HA- $\mathrm{MnO}_{2}$ NPs in various aqueous media: DDI water, saline ( $\mathrm{pH}=7.4$ ), and DMEM cell medium containing $10 \%$ fetal bovine serum. $\mathrm{MnO}_{2} \mathrm{NPs}$ undergo aggregation in saline and cell culture medium, Man-HA- $\mathrm{MnO}_{2}$ NPs are stable in these media. 

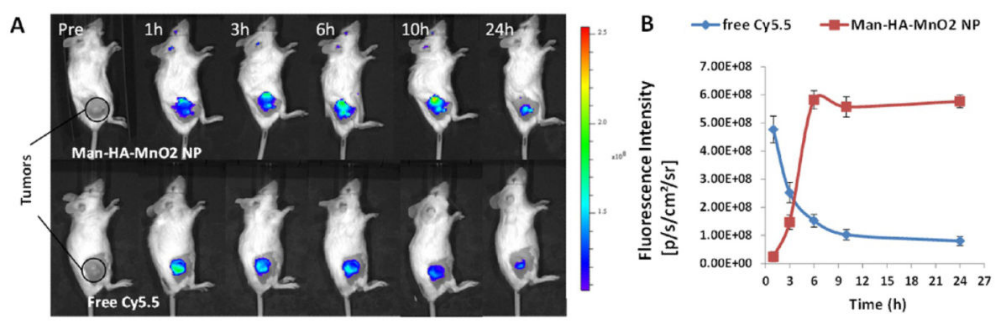

C
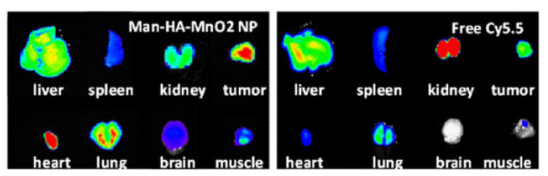

E

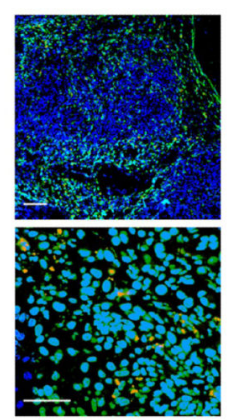

Figure 2.

Biodistribution of Man-HA- $\mathrm{MnO}_{2}$ NPs: (A) Representative optical images of 4T1 tumorbearing mice iv injected with Cy5.5-labeled Man-HA- $\mathrm{MnO}_{2} \mathrm{NPs}$ or free Cy5.5 at different time points. (B) A steady increase of tumor uptake of Man-HA- $\mathrm{MnO}_{2} \mathrm{NPs}$ after iv injection, which peaked at $6 \mathrm{~h}$ and then plateaued over time. Free Cy5.5 dye showed an initial maximum of tumor fluorescence followed by rapid clearance with time. (C and D) Biodistribution of Man-HA- $\mathrm{MnO}_{2}$ NPs and free Cy5.5 at 24 h pi ( $n=3$ /group). Error bars are standard error of the mean. Man-HA-MnO 2 NPs demonstrated good tumor accumulation and relatively low liver uptake, whereas free Cy5.5 showed high kidney accumulation and low tumor retention. (E) Representative immunofluorescence images of tumor sections after Man-HA- $\mathrm{MnO}_{2}$ NP administration. Man-HA- $\mathrm{MnO}_{2}$ NPs (orange) were taken up by TAMs (green) which were identified by the staining of CD206 M2 macrophage marker. Magnification 100× (top); scale bar $100 \mu \mathrm{m}$. Magnification 600× (bottom); scale bar $20 \mu \mathrm{m}$. 
A
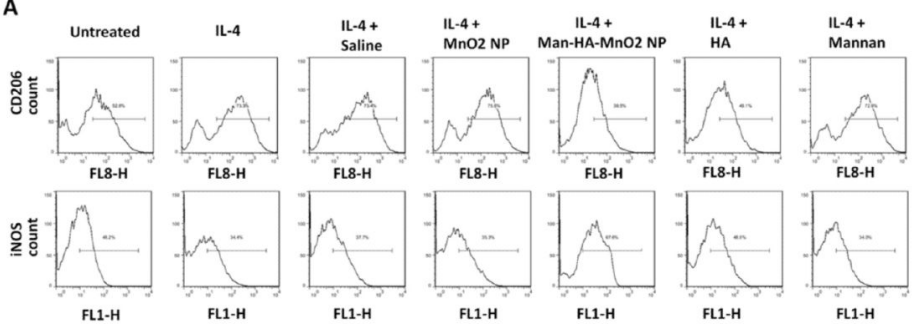

B

C
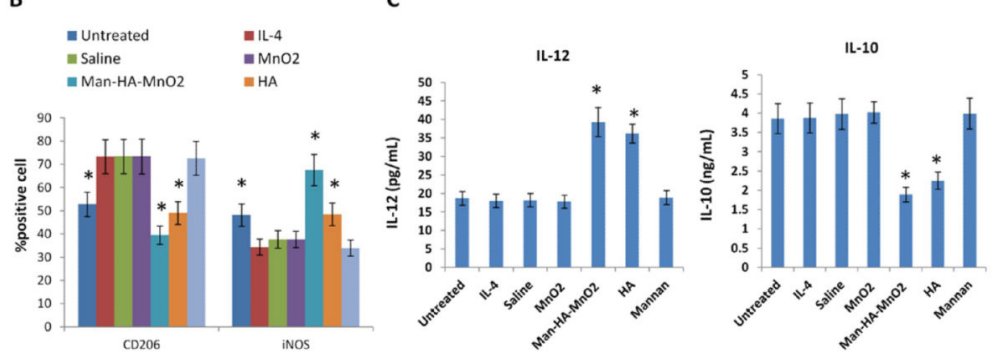

Figure 3.

Man-HA- $\mathrm{MnO}_{2}$ NPs prime M2 macrophages toward M1 macrophages: (A and B) Flow cytometric analysis of expression of iNOS (M1 macrophage marker) and CD206 (M2 macrophage marker) after administration of Man-HA-MnO $\mathrm{NPs}_{2}(5 \mu \mathrm{M} \mathrm{Mn}, 15 \mu \mathrm{M} \mathrm{HA})$, $\mathrm{MnO}_{2}$ NPs (5 $\left.\mu \mathrm{M} \mathrm{Mn}\right)$, HA (15 $\left.\mu \mathrm{M}\right)$ or mannan $(3 \mu \mathrm{M})$. Man-HA-MnO 2 NPs increased expression of iNOS and decreased expression of CD206. IL-4 switched RAW 264.7 cells to M2 phenotype. (C) Man-HA-MnO 2 NPs altered the cytokine secretion of M2 macrophage measured by ELISA ( $n=3$ /group). Error bars are standard error of the mean. $* p<0.05$ as compared to saline control. 

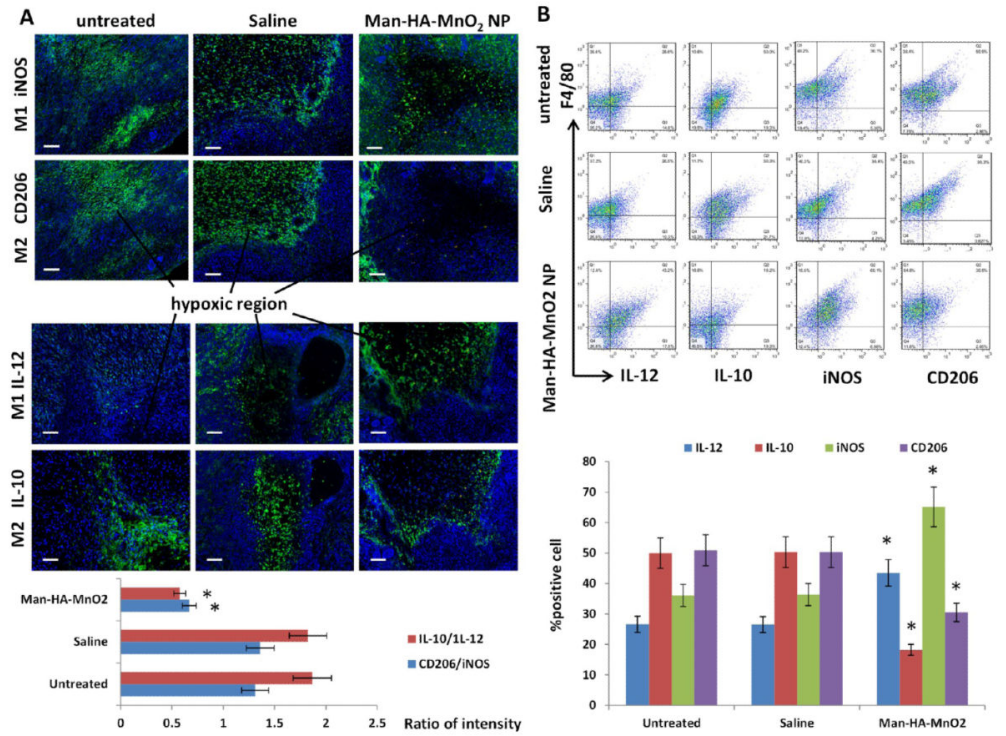

Figure 4.

Man-HA- $\mathrm{MnO}_{2}$ NPs skew TAMs M2 phenotype toward M1 phenotype: (A) Representative immunofluorescence images of tumor sections stained with M1 and M2 macrophage marker (green) after Man-HA-MnO $\mathrm{MP}_{2} \mathrm{NP}$ administration. The orange dots are Man-HA-MnO 2 NPs. Magnification $100 \times$; scale bar $100 \mu \mathrm{m}$. (B) Flow cytometric analysis of phenotype of macrophages in tumors after administration of Man-HA- $\mathrm{MnO}_{2} \mathrm{NPs}$ ( $n=5 /$ group). Error bars are standard error of the mean. $* p<0.05$ compared to untreated control. 


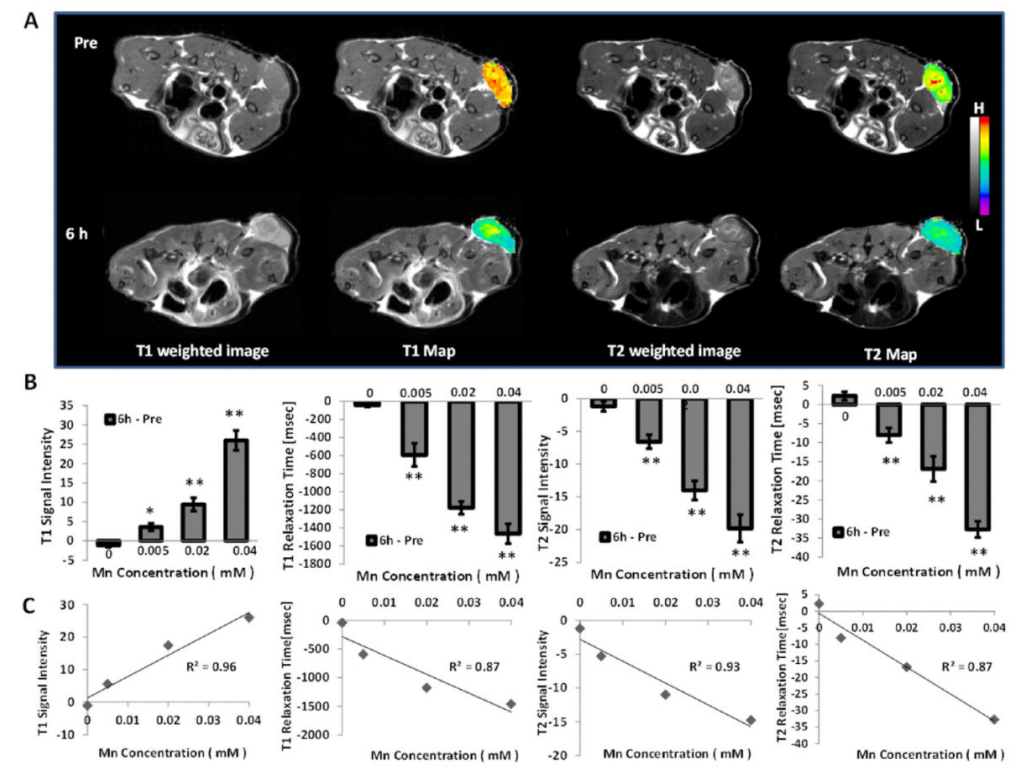

Figure 5.

Effect of Man-HA-MnO $\mathrm{MPs}_{2}$ on $T_{1}$ - and $T_{2}$-weighted MR signals, and $T_{1}$ and $T_{2}$ relaxation of tumors: (A) Representative $T_{1}$ - and $T_{2}$-weighted MR images and $T_{1}$ and $T_{2}$ maps of tumors before and $6 \mathrm{~h}$ after iv injection of Man-HA-MnO ${ }_{2}$ NPs. (B) The significant enhancements of $T_{1}$ - and $T_{2}$-weighted MRI contrast signals of tumors and dramatic changes in $T_{1}$ and $T_{2}$ values of tumors in a NP dose-dependent manner at $6 \mathrm{~h}$ after injection of ManHA- $\mathrm{MnO}_{2}$ NPs ( $n=5$ /group). Error bars are standard error of the mean. $* p<0.05$, ** $p<$ 0.005 of $T_{1}$ - and $T_{2}$-weighted MR images and $T_{1}$ and $T_{2}$ values as compared to the saline group. (C) A linear association between the NP dose and the change in the $T_{1}$ and $T_{2}$ relaxation rate $\left(\Delta T_{1}\right.$ and $\left.\Delta T_{2}\right)$ of tumor. 


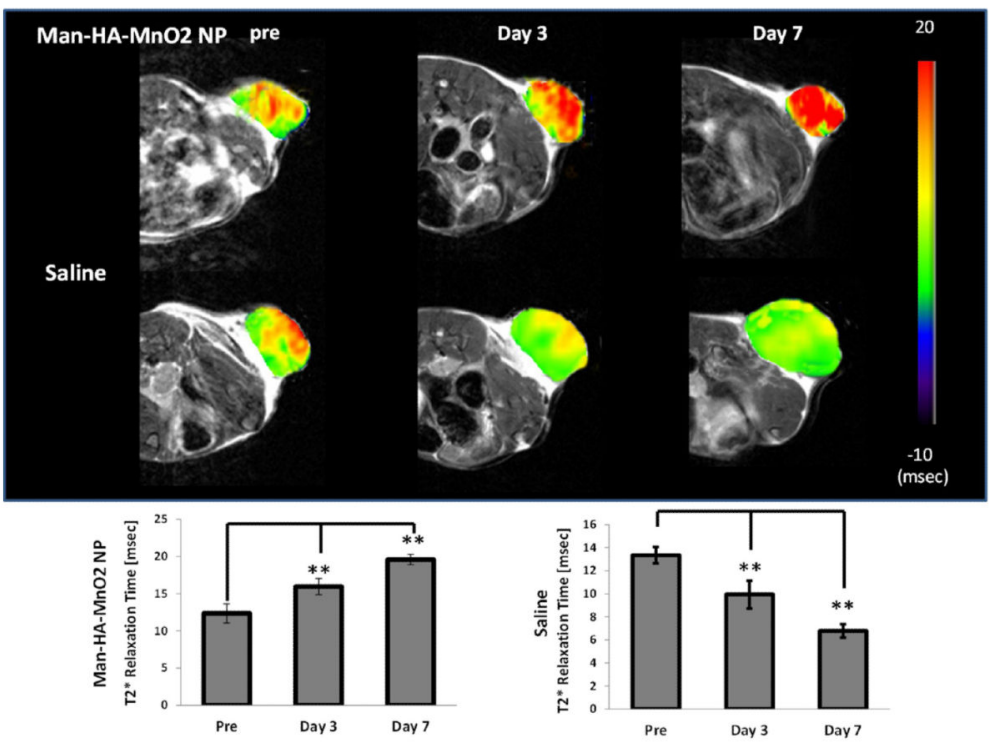

Figure 6.

Effect of Man-HA-MnO ${ }_{2}$ NPs on tumor oxygen on day 3 and day 7 after iv injection of Man-HA- $\mathrm{MnO}_{2}$ NPs: A significant increase in $T_{2}{ }^{*}$ values of tumors treated with Man-HA$\mathrm{MnO}_{2} \mathrm{NPs}$ at 3 and 7 days after iv injection of Man-HA-MnO${ }_{2} \mathrm{NPs}$ ( $n=5$ /group). Error bars are standard error of the mean. $* * p<0.005$ as compared to pretreatment. 

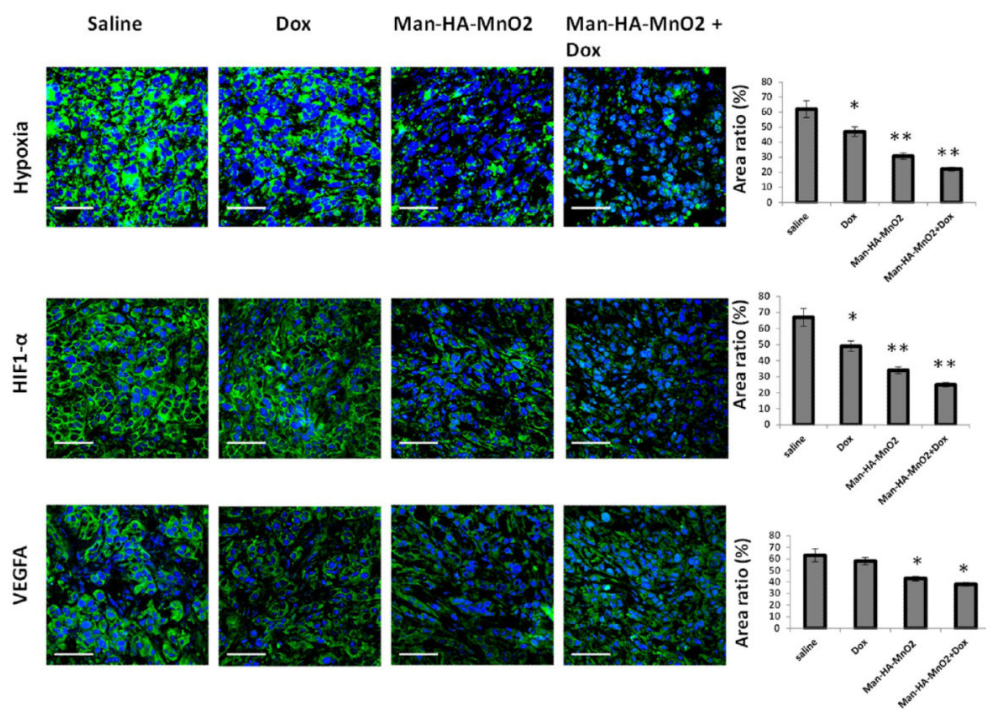

Figure 7.

Effect of Man-HA-MnO 2 NPs on tumor hypoxia, HIF-1 $a$ and VEGF: Representative immunofluorescense images of tumors treated with Man-HA- $\mathrm{MnO}_{2}$ NPs + Dox, Man-HA$\mathrm{MnO}_{2} \mathrm{NPs}$, Dox or saline on day 4. Tumor hypoxia was determined by Pimonidazole binding of HIF-1 $a$ and VEGF antibody staining. Magnification 600x; scale bar $20 \mu \mathrm{m}$. Error bars represent standard errors of the mean. $* p<0.05, * * p<0.005$ as compared to saline control. 


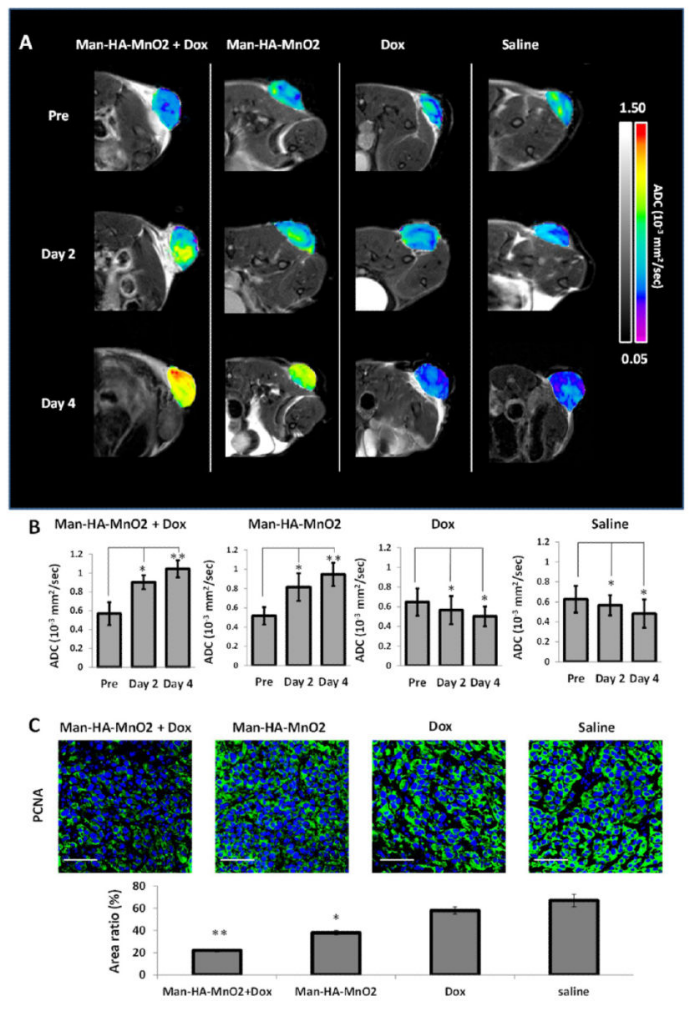

Figure 8.

Effect on apparent diffusion coefficient (ADC) of tumors and tumor cell proliferation after treatment with Dox and Man-HA-MnO 2 NPs: (A) Changes of apparent diffusion coefficient (ADC) of tumors on day 2 and day 4 after treatment with Dox and Man-HA-MnO 2 NPs. (B) The significant increase in ADC values after treatment with the combination of Man-HA$\mathrm{MnO}_{2}$ NPs with Dox at day 2 and day 4. (C) Effect of Man-HA-MnO${ }_{2}$ NPs and Dox on tumor cell proliferation determined by immunofluorescence staining with PCNA antibody. Magnification 600x; scale bar $20 \mu \mathrm{m}$. Error bars are standard error of the mean. $* p<0.05$, $* * p<0.005$ of ADC values as compared to pretreatment. 


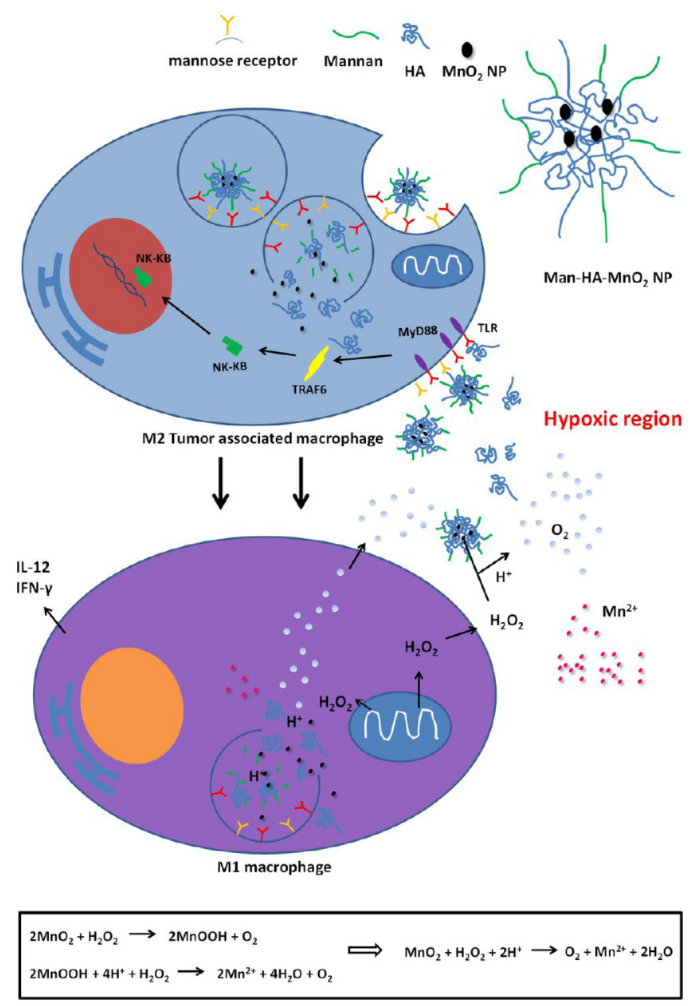

Scheme 1.

Multifunctionality of Man-HA-MnO $2 \mathrm{NPs}^{a}$

${ }^{a} \mathrm{MnO}_{2}$ particles $(\sim 15 \mathrm{~nm})$ are entrapped in hyaluronic acid (HA) with mannan molecules attached. When Man-HA- $\mathrm{MnO}_{2}$ NPs are recognized and uptaken by mannose receptor of TAMs, hyaluronic acid (HA) reprograms anti-inflammatory, pro-tumoral M2 TAMs to proinflammatory, antitumor M1 macrophages, which might be via a TLR2-MyD88-IRAK1TRAF6-PKC $\zeta$-NK- $x$ B-dependent pathway. The reprogrammed M1 macrophages secrete high level of IL-12, IFN- $\gamma$ and $\mathrm{H}_{2} \mathrm{O}_{2}$. The high reactivity of $\mathrm{MnO}_{2} \mathrm{NPs}$ toward $\mathrm{H}_{2} \mathrm{O}_{2}$ allows for the simultaneous production of $\mathrm{O}_{2}$ and $\mathrm{Mn}^{2+}$ ions and regulation of $\mathrm{pH}$ of tumor hypoxia. Once $\mathrm{MnO}_{2} \mathrm{NPs}$ are reduced into $\mathrm{Mn}^{2+}$ ions, they exhibit strong enhancement in both $T_{1}$ - and $T_{2}$-weighted MRI. 


\section{Table 1}

Particle Size and Zeta Potential of $\mathrm{MnO}_{2}$ NPs, HA-MnO 2 NPs, and Man-HA-MnO $\mathrm{NPs}_{2}(\mathrm{Mean} \pm \mathrm{SD}, n=3)$

\begin{tabular}{lrc}
\hline sample & mean particle size $(\mathbf{n m})$ & zeta potential $(\mathbf{m V})$ \\
$\mathrm{MnO}_{2} \mathrm{NPs}$ & $15 \pm 3.2$ & $+28.7 \pm 1.32$ \\
$\mathrm{HA}-\mathrm{MnO}_{2} \mathrm{NPs}$ & $180 \pm 5.6$ & $-36.5 \pm 4.22$ \\
$\mathrm{Man}-\mathrm{HA}-\mathrm{MnO}_{2} \mathrm{NPs}$ & $203 \pm 4.6$ & $-11.5 \pm 2.23$ \\
\hline
\end{tabular}

